Received: 08.12 .2017

Revised: 30.03 .2018

Accepted: 06.04.2018

DOI: $10.17804 / 2410-9908.2018 .2 .042-082$

\title{
DYNAMIC POWDER COMPACTION PROCESSES
}

\author{
A. P. Polyakov \\ Institute of Engineering Science, Ural Branch of the Russian Academy of Sciences, \\ 34 Komsomolskaya St., Ekaterinburg, Russian Federation \\ D http://orcid.org/0000-0003-0109-6916 هap@imach.uran.ru \\ Corresponding author. E-mail: pap@imach.uran.ru \\ Address for correspondence: ul. Komsomolskaya, 34, 620049, Ekaterinburg, Russian Federation \\ Tel.:+7 34337450 51; fax: +7 3433745330
}

Mathematical models of dynamic compaction and extrusion of incompact metallic materials are considered. According to the model of dynamic compaction, irreversible material volume changes occurring under the shock action are considered on the basis of the general equations of mass, momentum and energy conservation, which are written for the discontinuity surface.

A mathematical model of impact extrusion of incompact wire stock through a conical die is proposed. It is based on the superposition of the solutions of two problems, namely, compaction of powder material in a cylindrical press mold and impact extrusion of an incompressible material. The model allows one to determine the minimum tool velocity required to perform extrusion.

Keywords: powder material, dynamic compaction, shock wave, tool speed, porosity, extrusion.

\section{References}

1. Krupin A.V., Solovyev V.Ya., Popov G.S., Kr"stev M.R. Obrabotka metallov vzryvom [Explosion Processing of Metals]. Moscow, Metallurgiya Publ., 1991, 496 p. (In Russian).

2. Dmitriev A.M., Vorontsov A.L. Tekhnologiya kovki i obyemnoy shtampovki. Ch. 1. Obyemnaya shtampovka vydavlivaniem: ucheb. dlya vuzov [Technology of Forging and Bulk Stamping. Part 1. Bulk Stamping by Extrusion: Textbook for Colleges]. Moscow, Vysshaya Shkola Publ., 2002, 400 p. (In Russian).

3. Roman O.V., Gorobtsov V.G. Aktualnye problemy poroshkovoi metallurgii [Actual problems of powder metallurgy, eds., O.V. Roman, V.S. Arunachalam,]. Moscow, Metallurgiya Publ., 1990, pp. 78-99.

4. Belyakov G.V., Rodionov V.N., Samosadnyi V.P. Heating of porous material under impact compression. Combustion explosion and shock waves, 1977, vol. 13, iss. 4, pp. 524-528. DOI: $10.1007 / \mathrm{BF} 00744803$.

5. Gerasimov A.V., Krektuleva R.A. Numerical simulation of deformation and destruction of functionally gradient porous materials under explosive and impact loading. Mekhanika kompozitsionnykh materialov i konstruktsiy, 1999, vol. 5, no. 3, pp. 94-106. (In Russian).

6. Alekseev Yu.L., Ratnikov V.P., Rybakov A.P. Shock adiabats of porous metals. Journal of Applied Mechanics and Technical Physics, 1971, vol. 12, no. 2, pp. 257-262. DOI: 10.1007/BF00850698.

7. Anisichkin V.F. Shock compression of porous bodies. Combustion explosion and shock waves, 1979, vol. 15, no. 6, pp. 796-799. DOI: 10.1007/BF00739873.

8. $\quad$ Fomin V.M., Gulidov A.I., Sapozhnikov G.A., Shabalin I.I., Babakov V.A., Kuropatenko V.F., Kiselev A.B., Trishin Yu.A., Sadyrin A.I., Kiselev S.P.,Golovlev I.F. Vysokoskorostnoe vzai- 
modeistvie tel [High-speed interaction of bodies]. Novosibirsk, Siberian Branch of the Russian Academy of Sciences, 1999, 600 p. (In Russian).

9. Deribas A.A., Staver A.M. The shock compression of porous cylindrical bodies. Phizika Goreniya i Vzryva, 1974, vol. 10, no. 4, pp. 568-578. (In Russian).

10. Kuzmin G.E., Staver A.M. To the determination of flow parameters in shock-loaded powder materials. Fizika Goreniya i Vzryva, 1973, vol. 9, no. 6, pp. 898-905. (In Russian).

11. Yakovlev S.P., Kukhar V.D., Proskuryakov N.E., Seledkin E.M., Nechepurenko N.G. Magnito-impulsnaya shtampovka polykh tsilindricheskykh zagotovok [Magnetic Pulse Forming of Hollow Cylindrical Blanks]. Tula, Reproniks Ltd. Publ., 1998, 240 p. (In Russian).

12. Nesterenko V.F. Impul'snoe nagruzhenie geterogennykh materialov [Pulse loading of heterogeneous materials]. Novosibirsk, Nauka Publ., 1992, 200 p. (In Russian).

13. Roman O.V., Mirilenko A.P., Pikus I.M. Theory and technology of the component formation process - effect of high-speed loading conditions on the pressing mechanism. Soviet Powder Metallurgy and Metal Ceramics, 1989, vol. 28, no. 11, pp. 840-844. DOI: 10.1007/BF01198890.

14. Serdyuk G.G., Svistun L.I. Shock compaction of metal powders (theoretical research). In: Reologicheskie modeli $i$ protsessy deformirovoniya poristykh $i$ kompozitsionnykh materialov. Kiev, Naukova Dumka Publ., 1985, pp. 115-126. (In Russian).

15. Hermann W. Constitutive equation for the dynamic compaction of ductile porous materials. Journal of Applied Physics, 1969, vol. 40, no. 6, pp. 2490-2499. DOI: 10.1063/1.1658021.

16. Shtertser A.A. Transmission of pressure in porous-media under explosive loading. Combustion explosion and shock waves, 1988, vol. 24, iss. 5, pp. 610-615.

17. Butcher B.M., Carroll M.M., Holt A.C. Shock wave compaction of porous aluminum. J. Appl. Phys., 1974, vol. 45, no. 9, pp. 3864-3875. DOI: 10.1063/1.1663877.

18. Carroll M.M., Holt A.C. Steady waves in ductile porous solids. J. Appl. Phys., 1973, vol. 44, no. 10, pp. 4388-4392. DOI: 10.1063/1.1661970.

19. Davison L. Shock-wave structure in porous solids. J. Appl. Phys., 1971, vol. 42, no. 13, pp. 5503-5512. DOI: 10.1063/1.1659971.

20. Hǿrlück S., Dimon P. Statistics of shock waves in a two-dimensional granular flow. Physical Review E, 1999, vol. 60, no. 1, pp. 671-686. DOI: 10.1103/PhysRevE.60.671.

21. Nunziato J.W., Walsh E.K. One-dimensional shock waves in uniformly distributed granular materials. International Journal of Solids and Structures, 1978, vol. 14, no. 8, pp. 681-689. DOI: 10.1016/0020-7683(78)90006-9.

22. Ayzenberg-Stepanenko M.V., Osharovich G.G., Sher E.N., Yanovitskaya Z.Sh. Numerical Simulation of Shock-Wave Processes in Elastic Media and Structures. Part I: Solving Method and Algorithms. Journal of Mining Science, 2012, vol. 48, no. 1, pp. 76-95. DOI: 10.1134/S1062739148010091.

23. Afanas'eva S.A., Belov N.N., Burkin V.V., Dudarev E.F., Ishchenko A.N., Rogaev K.S., Tabachenko A.N., Khabibullin M.V., Yugov N. T. Simulation of the action of a shock wave on titanium alloy. Journal of Engineering Physics and Thermophysics, 2017, vol. 90, no. 1, pp. 24-34. DOI: 10.1007/s10891-017-1535-8.

24. Roman O.V., Shmuradko V.T., Tarasov G.D. Curve of the dynamic compressibility of powder media. Journal of Engineering Physics and Thermophysics, 2006, vol. 79, no. 4, pp. 817-823.

25. Chikova O.A., Shishkina E.V., Petrova A.N., Brodova I.G. Measuring the Nanohardness of Commercial Submicrocrystalline Aluminum Alloys Produced by Dynamic Pressing. The Physics of Metals and Metallography, 2014, vol. 115, no. 5, pp. 523-528. DOI: 10.1134/S0031918X14050044.

26. Shorokhov E.V., Zhgilev I.N., Gunderov D.V., Gurov A.A. Dynamic Pressing of Titanium for Producing an Ultrafine-Grained Structure. Russian Journal of Physical Chemistry B, 2008, vol. 2, no. 2, pp. 251-254. DOI: 10.1134/S1990793108020139.

27. Rogozin V.D. Vzryvnaya obrabotka poroshkovykh materialov [Explosive Processing of Powder Materials]. Volgograd, Polytekhnik Publ., 2002, 136 p. (In Russia). 
28. Kinelovskii S.A., Maevskii K.K. Model of the behavior of the mixture with different properties of the species under high dynamic loads. Journal of Applied Mechanics and Technical Physics, 2013, vol. 54, no. 4, pp. 524-530. DOI: 10.1134/S0021894413040020.

29. Vogler T. Shock Wave Perturbation Decay in Granular Materials. J. dynamic behavior mater., 2015, vol. 1, pp. 370-387. DOI: 10.1007/s40870-015-0033-3.

30. Shtern M.B., Kartuzov E.V. Formation and propagation of shock waves in highly porous materials. Powder Metallurgy and Metal Ceramics, 2016, vol. 55, no. 3-4, pp. 134-140. DOI: $10.1007 / \mathrm{s} 11106-016-9788-x$.

31. Leitsin V.N. A model of reacting powder medium. In: Vestnik Tomskogo Gosudarstvennogo Universiteta. Byulleten Operativnoi Tekhnicheskoi Informatsii [Bulletin of Tomsk State University: technical newsletter]. Tomsk, TGU Publ., 2001, no. 5, 40 p. (In Russian).

32. Boltachev G.Sh., Kaygorodov A.S., Volkov N.B. Densification of the granular medium by the low amplitude shock waves. Acta Mechanica, 2009, vol. 207, pp. 223-234. DOI: 10.1007/s00707-008-0127-2. 33. Boltachev G.Sh., Volkov N.B., Ivanov V.V., Kaygorodov A.S. Shock-wave compaction of the granular medium initiated by magnetically pulsed accelerated striker. Acta Mechanica, 2009, vol. 204, pp. 37-50. DOI: 10.1007/s00707-008-0046-2.

34. Olevsky E.A., Bokov A.A., Boltachev G.Sh., Volkov N.B., Zayats S.V., Ilyina A.M., Nozdrin A.A., Paranin S.N. Modeling and optimization of uniaxial magnetic pulse compaction of nanopowders. Acta Mech., 2013, vol. 224, pp. 3177-3195. DOI 10.1007/s00707-013-0939-6

35. Boltachev G.Sh., Volkov N.B., Chingina E.A. Nanopowders in Dynamic Magnetic Pulse Compaction Processes. Nanotechnologies in Russia, 2014, vol. 9, no. 11-12, pp. 650-659. DOI: $10.1134 / \mathrm{S} 1995078014060056$.

36. Bokov A.A., Boltachev G.Sh., Volkov N.B., Zayats S.V., Il'ina A.M., Nozdrin A.A., Paranin S.N., Olevskii E.A. Uniaxial Compaction of Nanopowders on a Magnetic_Pulse Press. Technical Physics, 2013, vol. 58, no. 10, pp. 1459-1468. DOI: 10.1134/S106378421310006X.

37. Fedotov A.F., Amosov A.P., Radchenko V.P. Modelirivanie protsessa pressovaniya poroshkovykh materialov $v$ uslovuyakh samorasprostranyayuschegosya vysokotemperaturnogo sinteza [Modeling the Powder Material Compaction in Conditions of the Self-Propagating HighTemperature Synthesis]. Moscow, Mashinostroenie-1 Publ., 2005, 282 p. (In Russian).

38. Kiselev A.B., Yumashev M.V Deformation and Failure under Impact Loading. Model of a Thermoelastoplastic Medium. Prikladnaya Mekhanika i Tekhnicheskaya Phizika, 1990, vol. 31, no. 5, pp. 116-123. (In Russian).

39. Godunov S.K., Romenskii E.I. Elementy mekhaniki sploshnykh sred i zakony sokhraneniya [Elements of continuum mechanics and conservation laws]. Novosibirsk, Nauchnaya Kniga Publ., 1998, 267 p. (In Russian).

40. Bardet J.P., Proubet J. Application of micromechanics to incrementally nonlinear constitutive equations for granular media. In: J. Biarez, R. Gourvès, eds. Powders and Grains, Int. Conf. on micromechanics of granular media, Clermont-Ferrand, 4-8 September, 1989: Proceedings., pp. 265-273.

41. Resnyansky A.D., Bourne N.K. Shock-wave compression of a porous material. J. Appl. Phys., 2004, vol. 95, no. 4, pp. 760-1769. DOI: 10.1063/1.1640460.

42. Boshoff-Mostert L., Viljoen H. J. Comparative study of analytical methods for Hugoniot curves of porous materials. J. Appl. Phys., 1999, vol. 86, no. 3, pp. 1245-1254. DOI: $10.1063 / 1.370878$.

43. Fenton G., Grady D., Vogler T. Shock Compression Modeling of Distended Mixtures. Journal of Dynamic Behavior Materials, 2015, vol. 1, pp. 103-113. DOI: 10.1007/s40870-015-0021-7.

44. Shen A.H., Ahrens T.J., O'Keefe J.D. Shock wave induced vaporization of porous solids. J. Appl. Phys., 2003, vol. 93, pp. 5167-5174. DOI: 10.1063/1.1563035.

45. Nigmatulin R.I. Osnovy mekhaniki geterogennykh sred [Fundamentals of the Mechanics of Heterogeneous Media]. Moscow, Nauka Publ., 1978, 336 p. (In Russian). 
46. Dunin S.Z., Surkov V.V. Dynamics of the closing of pores at the shock-wave front. PMM Journal of Applied Mathematics and Mechanics, 1979, vol. 43, iss. 3, pp. 550-558. DOI: 10.1016/0021-8928(79)90103-5.

47. Kraiko A.N., Miller L.G., Shirkovskii I.A. About gas flow in porous media with surfaces of porosity Discontinuity. Prikladnaya Mekhanika i Tekhnicheskaya Phizika, 1982, no. 1, pp. 111-118. (In Russian).

48. Zhdanovich G.M. Theory of Compaction of Metal Powders, transl. Teoriya Pressovaniya Metallicheskikh Poroshkov [Theory of Metal Powder Pressing, 1969, pp. 1-262]. Foreign Technology Division, Wright-Patterson Air Force Base, OH, 1971.

49. Ivanov V.V., Nozdrin A.A. Method of determining dynamic adiabatic compression curves of powders. Technical Physics Letters, 1997, vol. 23, pp. 527-528. DOI: 10.1134/1.1261734.

50. Nowacki W.K. Stress Waves in Non-Elastic Solids, Pergamon Press, Oxford, U.K, 1978, $182 \mathrm{p}$.

51. Proskuryakov N.E., Orlov S.Yu., Cherevatyi R.S. The effect of deformation velocity on dynamic yield stress. In: Mekhanika deformiruemogo tverdogo tela i obrabotka metallov davleniem, Tula, Tulskii Gosudarstvennyi Universitet Publ., 2001, pp. 134-138. (In Russian).

52. Carroll M.M., Kim K.T., Nesterenko V.F. The effect of temperature on viscoplastic pore collapse. J. Appl. Phys., 1986, vol. 59, no. 6, pp. 1962-1967. DOI: 10.1063/1.336426.

53. Polyakov A.P., Zalazinskaya E.A. Dynamic compaction of compacts of non-compacted metal stock. Izv. Vyssh. Uchebn. Zaved. Tsvetn. Metall., 2003, no. 1, pp. 30-34. (In Russian).

54. Green R.J. A plasticity theory for porous solids. Int. J. Mech. Sci., 1972, vol. 14, iss. 4, pp. 215-224. DOI: 10.1016/0020-7403(72)90063-X.

55. Zalazinskii A.G., Polyakov A.A., Polyakov A.P. On plastic compression of a porous body. Mechanics of Solids, 2003, vol. 38, no. 1, pp. 101-110.

56. Kolachev B.A., Livanov V.A., Bukhanova A.A. Mekhanicheskie svoistva titana $i$ ego splavov [Mechanical Properties of Titanium and its Alloys]. Moscow, Metallurgiya Publ., 1974, 544 p. (In Russian).

57. Polyakov A.P., Mokrousova M.S. Mathematical modeling of the process of dynamic compaction of a powder material. Kuznechno-Shtampovochnoe Proizvodstvo. Obrabotka Materialov Davleniem, 2004, no. 2, pp. 20-22, 24-27. (In Russian).

58. Polyakov A.P. The effect of parameters of dynamic loading on the propagation character of shock waves in a powder. Russian Journal of Non-Ferrous Metals, 2009, vol. 50, no. 1, pp. 33-38. DOI: $10.3103 / \mathrm{S} 106782120901009 \mathrm{X}$.

59. Druyanov B.A. Prikladnaya teoriya plastichnosti poristykh tel [Applied Theory of Plasticity of Porous Bodies]. Moscow, Mashinostroenie Publ., 1989, 168 p. (In Russian).

60. Zalazinskii A.G., Plasticheskoe deformirovanie strukturno-neodnorodnykh materialov [Plastic Deformation of Structurally Nonuniform Materials]. Yekaterinburg, Ural. Otd. Ross. Akad. Nauk Publ., 2000, 492 p. (In Russian).

61. Polyakov A.P. Impact extrusion of rod stock through conical die. Izv. Vyssh. Uchebn. Zaved. Tsvetn. Metall., 2004, no. 4, pp. 50-54. (In Russian).

62. Grigor'ev A.K., Rudskoi A.I. Deformatsiya i uplotnenie poroshkovykh materialov [Deformation and Compaction of Powder Materials]. Moscow, Metallurgiya Publ., 1992, 192 p. (In Russian).

63. Polyakov A.P. Impact extrusion process of billet production from low compressible material. Izv. VUZov. Chernaya Metallurgiya, 2006, no. 3, pp. 32-37. (In Russian).

64. Polyakov A.P. Power Parameters of the Impact Pressing Process of an Incompact Wire Stock. Russian Journal of Non-Ferrous Metals, 2007, vol. 48, no. 2, pp. 136-142. DOI: $10.3103 / \mathrm{S} 1067821207020125$. 
Подана в журнал: 08.12.2017

УДК 539.37

DOI: $10.17804 / 2410-9908.2018 .2 .042-082$

\title{
ДИНАМИЧЕСКИЕ ПРОЦЕССЫ УПЛОТНЕНИЯ ПОРОШКОВ
}

\author{
А. П. Поляков \\ Федеральное государственное бюджетное учреждение науки Институт машиноведения \\ Уральского отделения Российской академии наук, ул. Комсомольская, 34, \\ Екатеринбург, Российская Федерация \\ http://orcid.org/0000-0003-0109-6916 ap@imach.uran.ru \\ Ответственный автор. Электронная почта: pap@imach.uran.ru \\ Адрес для переписки: 620049, Екатеринбург, ул. Комсомольская, 34, Российская Федерация \\ Тел.: +7 (343) 374-50-51; факс: +7 (343) 374-53-30
}

Рассмотрены математические модели динамического прессования и выдавливания некомпактных металлических материалов. В соответствии с моделью динамического прессования, происходящие под действием ударных волн, необратимые изменения объема в материале рассматриваются на основе общих уравнений сохранения массы, количества движения и энергии, записанных для поверхности разрыва.

Построена математическая модель процесса ударного выдавливания некомпактной заготовки через коническую матрицу. Она основывается на суперпозиции решений задачи о прессовании порошкового материала в цилиндрической пресс-форме и задачи об ударном выдавливании несжимаемого материала. Модель позволяет определить минимальную скорость инструмента, позволяющую осуществить выдавливание заготовки.

Ключевые слова: порошковый материал, динамическое прессование, ударная волна, скорость инструмента, пористость, выдавливание.

Финансирование: работа выполнена по теме 0391-2016-0004 (№ гос. регистрации ААААA18-118020790142-9).

\section{1. Введение}

Процессы динамического прессования нашли широкое применение в порошковой металлургии. Обработка металлов методами импульсного нагружения обладает рядом преимуществ по сравнению со статическими способами, позволяя отказаться от использования крупногабаритного и дорогостоящего оборудования, повысить производительность процесса и т. д. Процесс высокоскоростной деформации по сравнению со статическим обладает рядом особенностей, определяемых ударно-волновым характером нагружения. При разработке технологических параметров динамического прессования некомпактных материалов следует обеспечить режим нагружения, позволяющий получить заготовку с заданными свойствами. Необходимо исследовать влияние на процесс нагружения таких параметров как размеры и исходная пористость заготовки, давление и температура на фронте ударной волны, массовая скорость вещества, изменение предела текучести материала и его структуры в процессе деформации, трение заготовки об инструмент и т. д. [1]. Более подробно классификацию задач, решаемых при исследовании процессов динамического прессования можно найти в [2].

В случае химических и фазовых превращений процесс уплотнения сопровождается схлопыванием пор и интенсивным перемешиванием компонентов, трением на поверхности частиц и их деформацией. Это резко активирует процессы структурной перестройки, коэф- 
фициенты диффузии увеличиваются на несколько порядков, возрастает скорость химических и фазовых превращений. Различные процессы и их стадии требуют различного времени для своего развития, поэтому за короткие времена, характерные для взрывного нагружения, подобно тепловой инерции, не все процессы успевают развиться и вещество реагирует на нагрузку совсем иначе, чем при квазистатическом режиме.

Источником энергии при импульсном прессовании являются взрыв заряда взрывчатого вещества, энергия электрического разряда в жидкости, импульсное магнитное поле, сжатый газ, вибрация. В зависимости от источника энергии прессование называют взрывным, электрогидравлическим, электромагнитным, пневмомеханическим, вибрационным.

Передача давления на прессуемый порошок также может осуществляться различными способами: непосредственно от источника энергии, а также через промежуточную среду или тело. Во втором случае в качестве среды, передающей давление, часто используется жидкость, и прессование называют гидродинамическим. Наконец, давление может также передаваться и через твердое тело - например тонкую пластину, разгоняемую энергией взрыва. Отдельно следует выделить прессование на специальных установках типа «копр» массивным ударником, приводимым в движение с помощью порохов, сжатых газов и т. д. Более полный обзор и классификация методов импульсного прессования представлены в работе [3].

Уплотнение при импульсном прессовании, в отличие, например, от изостатического, не происходит одновременно по всему объему. По порошку перемещается ударная волна сжатия, при прохождении волны происходит локальный разогрев частиц порошка (иногда до точки плавления), происходит его частичное спекание [4]. Это облегчает процесс деформирования, позволяя обеспечить большее уплотнение, чем при статическом прессовании. В результате импульсного прессования плотность распределена в заготовке более равномерно, чем после статического [1]. При этом появляются сложности, связанные с необходимостью достижения высоких энергий и сложностью управления процессом на таких скоростях. Динамическая нагрузка может привести к нарушению сплошности порошковой заготовки $[1,5]$.

Сложность и многообразие происходящих при импульсном нагружении процессов обусловили в последние десятилетия значительное количество публикаций по данному вопросу [1, 3, 6-30]. Различные аспекты процесса ударного прессования, связанные с физикохимическими превращениями при ударе, происходящем при разогреве пористых сред, рассмотрены в работах $[4,12,31]$. Динамическое прессование используется при равноканальном угловом прессовании (РКУП) [26], используются магнитно-импульсные методы прессования порошков [11, 32-36]. Следует также упомянуть о процессе самораспространяющегося высокотемпературного синтеза (CBC). Обзор работ по этому вопросу приведен в [37]. В ряде работ рассматриваются вопросы, связанные с разрушением материалов при ударном воздействии. Предложена модель материала с градиентным изменением физико-механических свойств (в частности пористого), исследованы особенности деформирования и разрушения таких материалов под действием импульсных нагрузок, при этом рассмотрено напряженнодеформированное состояние на микроуровне [5]. Модель повреждаемой термоупруговязкопластической среды, описывающая микроразрушение структурно-неоднородного материала в процессе динамического деформирования, приведена также в работе[38].

Далее рассматриваются вопросы, связанные с определением энергосиловых параметров процесса динамического прессования некомпактных материалов, определение величины и характера распределения остаточной пористости, влияние сил трения. 


\section{2. Динамическое прессование порошкового материала в закрытой цилиндрической пресс-форме}

\section{1. Основные подходы при моделировании процессов динамического прессования и принятые допущения}

Решение задач динамического прессования некомпактного материала предполагает исследование процесса распространения ударных волн уплотнения. Для решения таких задач есть два основных подхода. Согласно первому подходу пористый материал рассматривается как идеальная сжимаемая жидкость, при этом для исследования процесса используются уравнения газовой динамики или гидродинамики, основанные на известных соотношениях Рэнкина-Гюгонио [6, 15, 39-41], другой подход связан с применением различных теорий пластичности $[14,17,18]$. Заметим, что оба подхода имеют свои достоинства и недостатки, определяемые кроме всего прочего классом решаемых задач. Первый подход оправдан, если рассматриваются сильные ударные волны с давлениями на фронте волны существенно больше 200-300 ГПа [39]. В этом случае металл становится «текучим», проявляет свойства «псевдожидкости». Правомерность гидродинамической аналогии зависит также от свойств прессуемого материала. Неслучайно идентификация таких моделей часто выполняется на вязких пластичных материалах, таких как алюминий, медь [6, 40-43]. Наилучшие результаты применения гидродинамической аналогии достигаются при решении задач динамики грунтов [44].

В ряде случаев гидродинамическая аналогия является неудовлетворительной. Так в работе [10] представлены результаты расчетных и экспериментальных исследований ударного сжатия железного порошка продуктами детонации конденсированных взрывчатым веществ. Процесс деформирования порошка изучен с позиций механики сплошной среды. Результаты признаны приемлемыми, если не исследуются структуры полей напряжений и деформаций на микроуровне. Показано, что для принятых условий эксперимента модели идеальной сжимаемой жидкости или вязкой жидкости являются неудовлетворительными.

В последнее время развивается подход, согласно которому процессы ударного сжатия некомпактного материала рассматриваются в рамках механики гетерогенных сред [12, 45], при этом существенное внимание уделяется динамике выборки пор [17, 31, 46, 47]. Однако решаемые задачи, как правило, связаны с исследованием структуры ударных волн в двухкомпонентных средах («твердое тело-газ» или «твердое тело-жидкость»).

Важно отметить, что при математическом моделировании процессов динамического прессования, как правило, не рассматривается вопрос о характере распределения остаточной пористости по высоте заготовки, обычно она принимается постоянной $[6,9,14,17,48,49]$. Между тем сложный волновой характер нагружения приводит к неравномерному распределению пористости, что подтверждается экспериментальными данными [1]. Неравномерность распределения остаточной пористости по высоте заготовки может отрицательно повлиять на потребительские свойства заготовки.

Для построения математических моделей динамического прессования используется подход, основанный на теории пластичности пористых тел. Решения, основанные на указанной теории, получены при следующих основных допущениях.

1. Изменение пористости под действием ударных волн происходит, когда вся заготовка переходит в пластическое состояние, упругими деформациями пренебрегают $[14,46]$.

2. Плотность среды после прохождения ударной волны остается постоянной $[10,50]$.

3. Эффекты, связанные с разогревом вещества, не учитываются $[3,15,17,18]$.

4. Предел текучести материала принимается по аналогии с решением квазистатической задачи $[14,17]$.

5. Трение в области контакта заготовки и пресс-формы не учитывается $[10,14,17]$. 
Относительно первых двух допущений заметим следующее. Ряд авторов считает необходимым учитывать также упругую составляющую ударной волны (упругий предвестник) $[16,39]$. Необходимость учета упругой составляющей ударной волны зависит от степени сжатия пористого тела (при больших необратимых деформациях упругими можно пренебречь). Допущение 3 справедливо при не очень высоких давлениях, в десятки килобар [46]. При этом локальный разогрев вещества, вызывающий частичное спекание, можно учесть в определяющих соотношениях.

Что касается допущения 4, изменение предела текучести при динамическом нагружении является известным фактом. Сложность состоит в конкретизации зависимости. В работе [48] предлагается ввести коэффициент динамичности $\kappa_{\partial}$ (отношение динамического $\sigma_{s}^{\partial}$ и статического $\sigma_{s}$ пределов текучести), причем его величина при взрывном прессовании является значительной, $\kappa_{\partial} \approx 3$. В работе [51] используется модель Соколовского-Малверна:

$$
\sigma_{s}^{\partial}=\sigma_{s}\left\{1+(\dot{\varepsilon} / D)^{1 / n}\right\}
$$

где $\dot{\varepsilon}$ - скорость деформации, а величины $D$ и $n$ определяются экспериментально.

В. Ф. Нестеренко в рамках построения модели деформирования гетерогенного материала при ударно-волновом нагружении предложена зависимость предела текучести от температуры в следующем виде [52]:

$$
\sigma_{s}=\sigma_{s 0}\left(1-T / T_{n л}\right)
$$

где $\sigma_{s 0}-$ предел текучести материала в холодном состоянии.

Автором при математическом моделировании процессов динамического прессования использованы зависимости вида:

$$
\sigma_{s}^{\partial}=\sigma_{s}\left(1+\lambda e^{p}\right)
$$

где $e^{p}$ - накопленная необратимая деформация; $\lambda$ - параметр, зависящий от пористости $\theta$.

Рассмотрим последнее допущение. При математическом моделировании процессов динамического прессования порошков принято считать, что влияние сил трения в этом случае значительно меньше, чем при статическом нагружении. Подобный вывод был сделан на основе результатов исследования процессов прессования при взрывном нагружении, при очень высоких скоростях, причем экспериментально определить влияние сил трения в этом случае очень сложно. Однако, если ударное прессование осуществляется массивным ударником (при меньшей скорости инструмента), неучет сил трения может привести к значительной ошибке. От величины коэффициента трения зависят энергосиловые параметры процесса. В моделях без трения остаточная пористость постоянна по высоте прессовки, что в той или иной степени не соответствует реальным процессам. В ряде случаев неравномерность распределения остаточной пористости по высоте заготовки может отрицательно повлиять на формирование ее поровой структуры и механические свойства.

Таким образом, при построении математических моделей процессов динамического прессования некомпактных материалов необходимо учитывать особенности ударноволнового характера нагружения, влияние скорости нагружения на предел текучести материала, силы трения, а также совместное влияние указанных факторов, как на величину, так и на характер распределения остаточной пористости. 


\section{2. Решение на основе уравнения баланса энергии}

В соответствии с работой [53] предположим, что пористое (пластически сжимаемое) тело, первоначально занимавшее объем с размерами $h_{0}$ и $2 R_{0}$, подвергается ударному воздействию со стороны инструмента (ударник + пуансон), движущегося поступательно вниз со скоростью $v_{h}=v_{h}(t)$ (рис. 1). В результате происходит уменьшение высоты заготовки на величину $\Delta h=h_{0}-h$, где $h$ - текущая высота заготовки.

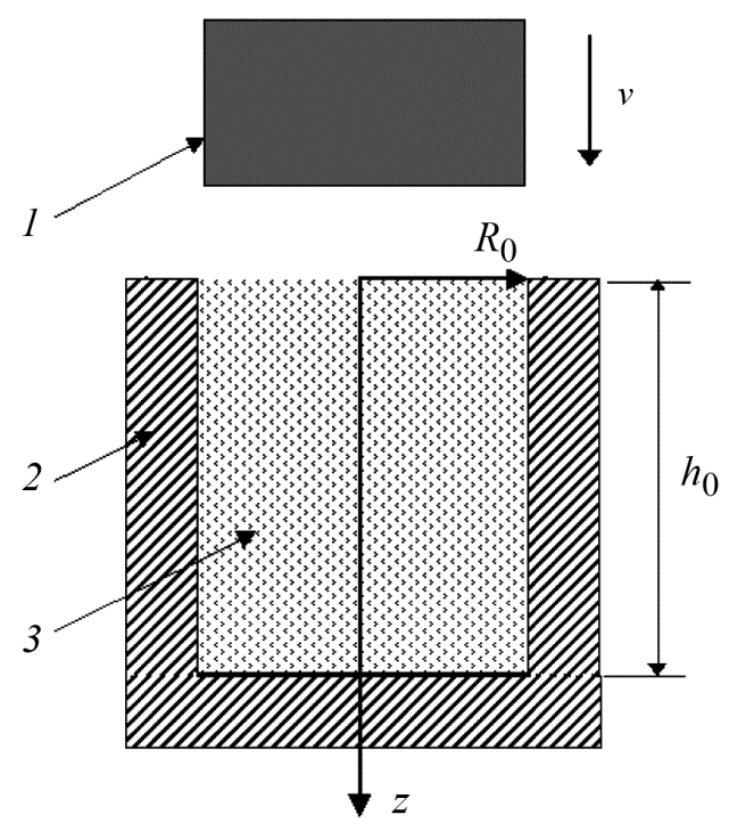

Рис. 1. Схема ударного прессования: 1 - ударник; 2 - контейнер; 3 - порошок

Примем, что на поверхности контакта заготовки с инструментом трение отсутствует, а на контакте заготовки с боковыми стенками пресс-формы действуют касательные напряжения трения $\tau_{\kappa}$, подчиняющиеся закону трения Зибеля: $\tau_{\kappa}=f \tau_{s}^{*}$, где $f$ - коэффициент пропорциональности. В силу осевой симметрии для решения задачи используем цилиндрическую систему координат $(r, \varphi, z)$. Одновременно введем сопутствующую безразмерную систему координат: $\left(\tilde{r}=r / R_{0}, \varphi, \tilde{z}=z / h_{0}\right)$.

Кинематически допустимое поле скоростей зададим в виде:

$$
v_{r}=v_{\varphi}=0 ; \quad v_{z}=-v_{h}(t) \varphi(\tilde{z}, \alpha),
$$

где $\alpha$ - варьируемый параметр, а функция $\varphi(z, \alpha)$ должна удовлетворять граничным условиям: $\varphi(0, \alpha)=0, \varphi(h, \alpha)=1$. Выберем ее в виде:

$$
\varphi(\tilde{z}, \alpha)=(z / h)[1-\alpha(1-(z / h))]=\tilde{z}[1-\alpha(1-\tilde{z})] .
$$

Используем условие текучести эллиптического типа и определяющие соотношения для пластически сжимаемого тела $[54,55]$ :

$$
\sigma^{2} /\left(\sigma_{s}^{*}\right)^{2}+\tau^{2} /\left(\tau_{s}^{*}\right)^{2}=1 ; \sigma_{s}^{*}=-(2 / \sqrt{3}) K_{2} \tau_{s} \ln (\eta / \theta) ; \tau_{s}^{*}=\tau_{s}\left(1-K_{1} \theta^{\varsigma}\right),
$$

где $\sigma, \tau$ - первый и второй инварианты тензора напряжений соответственно; $\tau_{s}^{*}$ и $\sigma_{s}^{*}-$ пределы текучести некомпактного материала на сдвиг и сжатие соответственно; $\tau_{s}-$ предел 
текучести на сдвиг компактного материала; $K, \varsigma, \eta$ - коэффициенты, характеризующие форму, расположение и различие в размерах пор.

Исходя из поля перемещений в соответствии с формулой получаем следующий закон распределения плотности по высоте заготовки:

$$
\rho=\rho_{0} /\left(1-\left(\Delta h / h_{0}\right)(1-\alpha+2 \alpha \tilde{z})\right)
$$

где $\rho$ - относительная плотность (плотность заготовки, отнесенная к $\rho_{\kappa}-$ плотности компактного материала); индекс «0» относится к начальному состоянию.

Из последней формулы определим диапазон допустимых значений параметра $\alpha$. Полагая, что разрыхления материала в процессе прессования не происходит, получаем: $\alpha \leq 1$. Значению $\alpha \geq 0$ соответствует ситуация, когда плотность заготовки максимальна в области ее контакта с инструментом и убывает по мере удаления от указанной зоны.

Для определения энергосиловых параметров и распределения остаточной пористости по высоте заготовки запишем уравнение баланса энергии:

$$
\int_{\Omega}\left[\tau H+\sigma \xi+\rho_{\kappa} w_{z} v_{z}\right] d \Omega-\left.\int_{S_{S}}\left(\sigma_{r z} v_{z}\right)\right|_{r=R} d S-\left.\int_{S_{V}}\left(\sigma_{z z} v_{z}\right)\right|_{z=h} d S=0,
$$

где $S_{v}$ - поверхность, на которой заданы граничные условия в скоростях; $S_{s}-$ поверхность, где задан закон трения; $\sigma_{z z}, \sigma_{r z}$ - нормальная и касательная компоненты тензора напряжений. Формула (3) справедлива в любой фиксированный момент времени $t$. Выразим из (3) величину контактного давления $\sigma_{z z \mid z=h}$. Получаем:

$$
\sigma_{z z \mid z=h}=-\frac{1}{\pi R^{2} v_{h}(t)}\left\{\int_{\Omega}\left[\left(\sigma-\frac{2}{\sqrt{3}} \tau\right) \xi+\rho_{\kappa} w_{z} v_{z}\right] d \Omega-\left.\int_{S_{S}}\left(\sigma_{r z} v_{z}\right)\right|_{r=R} d S\right\} .
$$

Поскольку момент времени фиксирован, считаем, что величины $v_{h}(t)$ и $\dot{v}_{h}(t)$ известны. Следовательно, правая часть формулы (4) содержит единственный неизвестный (варьируемый) параметр $\alpha$. Чтобы определить в каждый фиксированный момент времени величину давления необходимо минимизировать выражение в правой части формулы (4) относительно варьируемого параметра $\alpha$, при этом должно выполняться ограничение $\alpha \leq 1$. Решение построим следующим образом. Задаем малое перемещение $\Delta h$. По формуле (2) находим распределение плотности по высоте заготовки, которое будет начальным для следующего шага по времени (изменению $\Delta h$ ). Для определения значений скорости $v_{h}(t)$ и ускорения $\dot{v}_{h}(t)$, являющихся функциями времени, используем условие:

$$
\left.M_{u} \dot{v}_{z}\right|_{z=h}=\int_{S_{V}} \sigma_{z z \mid z=h} d S
$$

где $M_{u}$ - масса инструмента (полагаем $M_{u}>>m$, где $m$ - масса заготовки). Производную по времени в левой части (5) перепишем следующим образом: $d v_{z}(t) / d t=\left[d v_{z}(t) / d h\right][d h / d t]$. На контакте заготовки с инструментом $\left.v_{z}\right|_{z=h}=-v_{h}(t) \tilde{z}[1-\alpha(1-\tilde{z})]_{z=1}=-v_{h}(t)$, и ввиду малости $\Delta h$ можно считать, что $\Delta h \approx d h$. Получаем следующее дифференциальное уравнение: 


$$
\frac{d\left(\left[v_{h}(t)\right]^{2}\right)}{d h}=\frac{2}{M_{u}} \pi R^{2} \int \sigma_{z z \mid z=h} d z .
$$

Отсюда для малого промежутка времени имеем:

$$
v_{h}(t)=\sqrt{\left[v_{h}(0)\right]^{2}-\frac{2}{K_{\mu} \rho_{\kappa}\langle\rho\rangle}\left[\frac{\left.\sigma_{z z \mid z=h}(t)+\sigma_{z z \mid z=h}(0) \mid\right]}{2}\right] \frac{\Delta h}{h}},
$$

где перемещение $\Delta h$ соответствует моменту времени $t ; K_{м}=M_{u} / m$.

Для данного шага с малым перемещением $\Delta h$ известны все необходимые параметры (распределение плотности по высоте заготовки, поле напряжений, скорость перемещения инструмента). Задаем новое малое перемещение $\Delta h_{1}$; по известной скорости $v_{h}(t)$ к началу нового шага определяем величину ускорения $\dot{v}_{h}(t)$ и снова повторяем процедуру расчета. В качестве начального распределения плотности принимаем то, которое получено в конце предыдущего шага. Расчет продолжается, пока скорость $v_{h}(t)$ не станет достаточно малой.

Проверка адекватности модели путем сравнения расчетных и экспериментальных данных показала удовлетворительное количественное и качественное совпадение результатов [53].

Рассмотрим, как влияют на остаточную пористость заготовок коэффициент трения $f$ и начальная скорость пуансона $v_{h}(0)$. Скорость $v_{h}(0)$ варьировали в диапазоне 7,5-120 м/с при условии постоянства сообщаемой заготовке кинетической энергии $E_{\kappa}=\frac{M_{u}}{2}\left[v_{h}(0)\right]^{2}$.

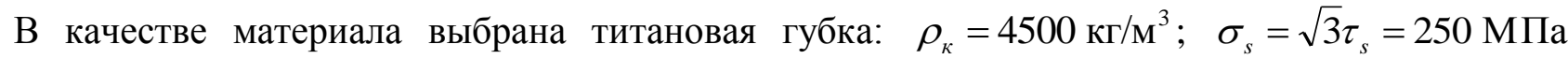
( $\sigma_{s}$ - предел текучести на одноосное растяжение/сжатие компактного материала) [56]. Результаты расчета средней остаточной пористости заготовок $\tilde{\theta}$ и ее изменения по высоте $\Delta \theta$ представлены на рис. $2 a$ и рис. $2 \sigma$ соответственно. Отметим, что при высоких начальных скоростях инструмента неравномерность распределения остаточной пористости по высоте возрастает. Ее величина может достигать $\Delta \theta=0,06 \div 0,08$ [53].

На рис. 2 в и рис. 2 г приведены результаты расчета ударного прессования заготовок до достижения средней остаточной пористости $\tilde{\theta} \approx 0,1$. Брикеты такой пористости можно использовать в качестве заготовок для последующего выдавливания прутков. Расчеты выполнены при начальной скорости инструмента $v_{h}(0) \in[120 ; 135] \mathrm{m} / \mathrm{c}$. Варьировали величину коэффициента трения $f$ и отношение начальных размеров заготовки $h_{0} / R_{0}$. Начальная пористость $\theta_{0} \approx 0,7$ (состояние свободной насыпки). На рис. 2 в приведена зависимость от величин $f$ и $h_{0} / R_{0}$ безразмерной энергии деформации $\tilde{E}$ (относительно энергии деформации процесса с минимальной начальной скоростью инструмента при отсутствии трения).

Из рис. 2 б и 2 г следует, что остаточная пористость может быть распределена существенно неравномерно по высоте заготовки. На рис. 3 показан характер изменения этой неравномерности в процессе деформирования. 


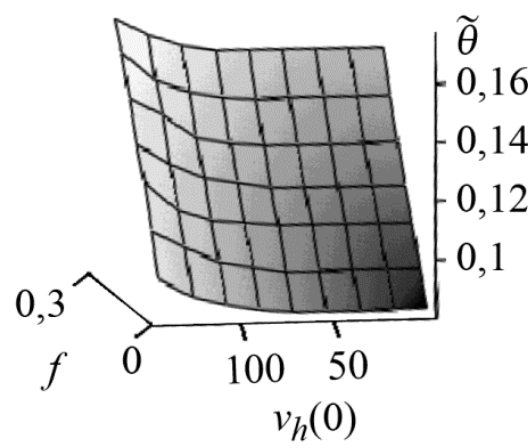

$a$

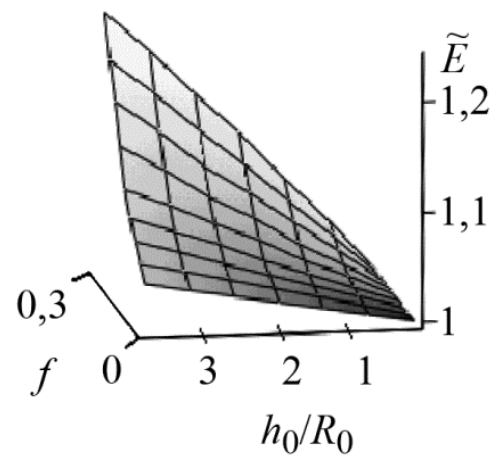

B

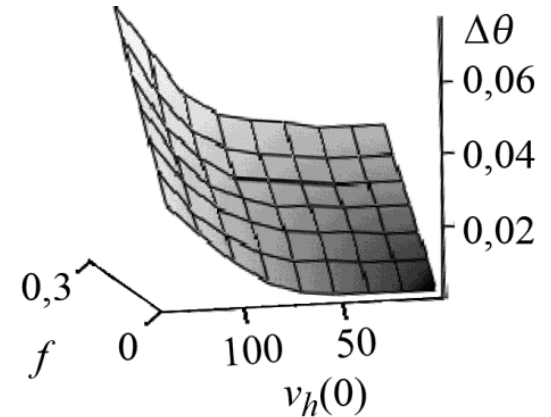

$\sigma$

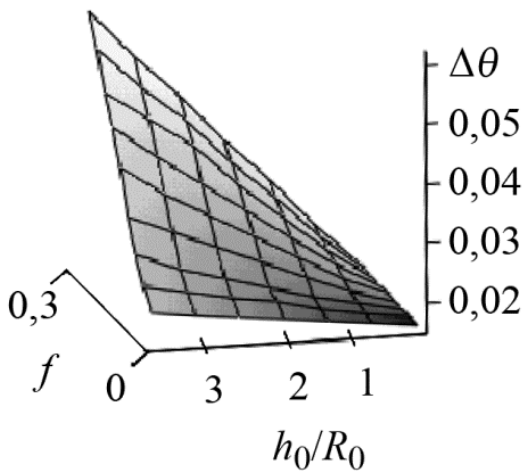

2

Рис. 2. Графики для оценки остаточной пористости заготовок, неравномерности ее распределения по высоте и энергии деформации

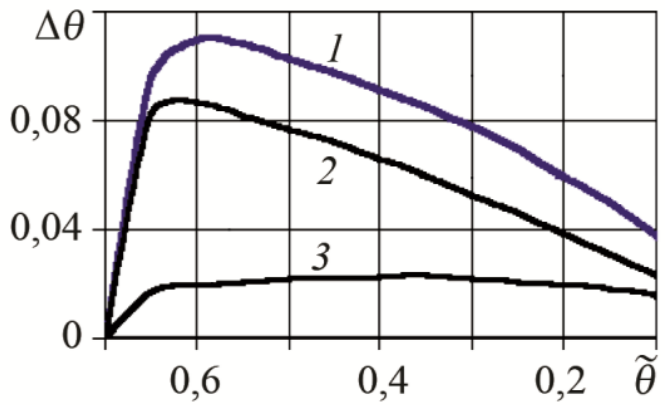

Рис. 3. Характер изменения неравномерности распределения пористости по высоте заготовки:

$1-v_{h}(0)=125 \mathrm{~m} / \mathrm{c}, f=0,3 ; 2-v_{h}(0)=125 \mathrm{~m} / \mathrm{c}, f=0 ; 3-v_{h}(0)=8 \mathrm{~m} / \mathrm{c}, f=0,3$

При малой начальной скорости и отсутствии трения процесс близок к квазистатическому, изменение пористости по высоте не превышает 0,005. При состояниях, близких к беспористому, плотность по высоте распределена достаточно равномерно. Для заготовок с малой остаточной пористостью $(\tilde{\theta} \leq 0,05)$ этот факт легко объяснить исходя из результатов, представленных на рис. 3. Однако, если остаточная пористость не слишком мала и трение значительно, ее распределение по высоте может оказаться существенно неравномерным (рис. 2 б, г). Это следует учитывать в частности при оценке потребительских свойств полученных заготовок. 


\section{3. Волновое решение}

Решение, представленное выше, количественно верно описывает энергосиловые параметры процесса динамического прессования. Однако оно имеет недостаток, заключающийся в том, что при отсутствии трения распределение пористости по высоте получается практически равномерным (при малых и умеренных скоростях инструмента), а при высоких скоростях и наличии трения более плотными всегда оказываются слои, непосредственно прилегающие к инструменту, что не соответствует реальным процессам.

Ниже в соответствии с [57] приведена математическая постановка решения задачи прессования в замкнутой пресс-форме, основанная на волновом представлении процесса. Рассмотрены случаи, когда давление на заготовку передается посредством массивного ударника, приводимого в движение, например, гидросистемой пресса, или же тонкой пластины, движущейся за счет использования энергии взрывчатых веществ.

Решение задачи динамического прессования порошков предполагает исследование процесса распространения ударных волн уплотнения. В этом случае происходящие под действием ударных волн необратимые изменения объема в материале рассматриваются на основе общих уравнений сохранения массы, количества движения и энергии, записанных для поверхности разрыва [50]. В соответствии с подходом, который принят за основу в представленном ниже решении, процессы ударно-волнового сжатия некомпактного материала рассматриваются в рамках механики гетерогенных сред [45].

Расчетная схема процесса соответствует рис. 1. Примем следующие допущения:

1) В исходном состоянии среда однородна, плотность постоянна.

2) Изменение плотности под действием ударных волн происходит, когда вся заготовка переходит в пластическое состояние, упругими деформациями пренебрегаем.

3) Пластические деформации локализованы на фронте ударной волны, за и перед фронтом ударной волны среда ведет себя как твердое тело.

4) Эффекты, связанные с разогревом вещества не учитываются.

Относительно правомерности 2-го и 3-го допущения заметим следующее. Известно, что заметное изменение пористости под действием ударных волн происходит, когда вся масса вещества переходит в пластическое состояние $[18,46]$, поэтому упругими деформациями в данном случае можно пренебречь. Кроме того, в работах ряда авторов отмечено, что плотность среды после прохождения волны уплотнения меняется незначительно. Например, для грунтов при высоких давлениях [50], для порошков при динамическом прессовании [10] и результаты работы [49] по динамическому сжатию наноразмерных порошков). Допущение 4 справедливо при не слишком высоких давлениях, порядка десятков килобар [39, 46].

Указанные допущения позволяют искать решение в аналитическом виде и одновременно учесть характерные особенности, связанные с динамикой процесса.

Рассмотрим процесс распространения ударной волны в идеальном пластически сжимаемом материале. Для любой точки среды в области непрерывных движений справедливы дифференциальные уравнения движения:

$$
\sigma_{j i, j}=\rho \frac{\partial v}{\partial t}+\rho v_{i, j} v_{j}
$$

Поскольку $v_{z}=$ const (допущение 2), проинтегрируем уравнение (7) по координате " $z$ ". Без трения с учетом закона сохранения массы $\int_{\Omega} \rho d \Omega=$ const имеем:

$$
\sigma_{z z}=\rho_{0} \frac{\partial v_{z}}{\partial t} z-p(t)
$$

где $p(t)=-\left.\sigma_{z z}(z, t)\right|_{z=0}-$ давление в зоне контакта порошка и инструмента. 
Координаты точек, принадлежащих ударной волне, являются функциями времени. Обозначим их $z=\varphi(t)$. Известные соотношения на ударной волне имеют вид:

$$
\begin{gathered}
\rho\left\{v-\varphi^{\prime}(t)\right\}=-\rho_{0} \varphi^{\prime}(t) \\
\sigma_{z z}-\sigma_{z z}\left(\rho_{0}\right)=\rho\left\{v-\varphi^{\prime}(t)\right\} v=-\rho_{0} \varphi^{\prime}(t) v^{\prime}
\end{gathered}
$$

где $\left(\sigma_{z z}\left(\rho_{0}\right)\right.$ - напряжение в упругой волне, соответствующее переходу среды в пластическое состояние при плотности $\rho_{0},()^{\prime}=\partial / \partial t$.

С учетом закона движения инструмента в виде (5) $p(t)=-M_{u} v^{\prime} / S$. Обозначив $A=M_{u} /\left[\left(1-\theta_{0}\right) \rho_{\kappa} S\right]$ и $B=\sigma_{z z}\left(\theta_{0}\right) /\left[\left(1-\theta_{0}\right) \rho_{\kappa}\right]$, где $S$ - площадь поперечного сечения заготовки, имеем:

$$
A v^{\prime}=-\{\varphi(t) v\}^{\prime}+B
$$

Далее получаем выражение для массовой скорости:

$$
v=\left(A v_{0}+B t\right) /(A+\varphi(t)) .
$$

Уравнение ударной волны записываем следующим образом:

$$
\varphi(t)=A \beta \tilde{t} /\left(v_{0}-\beta \tilde{t}\right),
$$

где $\tilde{t}=t / t_{b}, t_{b}$ - время распространения пластической ударной волны по частицам среды; $t_{B}=-A v_{0} / B$.

При этом скорость распространения ее фронта равна [57]:

$$
\varphi^{\prime}(t)=-B \beta /\left(v_{0}-\beta \tilde{t}\right)^{2},
$$

где $\beta=-\varphi^{\prime}(0)\left(v_{0}\right)^{2} / B$.

Плотность при прохождении ударной волны определяем в виде:

$$
\rho=\rho_{0} \frac{\varphi^{\prime}(0)\left(v_{0}\right)^{2}}{\varphi^{\prime}(0)\left(v_{0}\right)^{2}-\left(1+B \frac{\varphi(t)}{(A+\varphi(t)) \varphi^{\prime}(0) v_{0}}\right)\left(\frac{A v_{0}}{A+\varphi(t)}\right)^{3}} .
$$

Выражение, учитывающее неравномерность остаточной пористости при импульсном прессовании приведено также в работе [1]. Оно получено в предположении линейной связи между скоростью фронта ударной волны и массовой скоростью вещества. Недостаток такого подхода отмечен выше. Кроме того, не приведены результаты конкретного применения зависимости.

В рамках построенной модели можно учесть влияние сил трения. Предположим, что на контакте с боковыми стенками контейнера действуют касательные напряжения трения $\sigma_{r z}$, подчиняющиеся закону трения Зибеля. Зададим их в виде $\sigma_{r z}=-f \tau_{s}^{*}(r / R)$. Тогда уравнение (8) примет вид:

$$
\sigma_{z z}-\frac{2 f}{R} \int_{0}^{z} \tau_{s}^{*} d z=\rho_{0} \frac{\partial v_{z}}{\partial t} z-p(t)
$$


Введем величину $B^{*}=B-\frac{2 f}{R} \int_{0}^{z} \tau_{s}^{*} d z /\left\{\left(1-\theta_{0}\right) \rho_{\kappa}\right\}$ и, считая $B^{*}$ некоторой неизвестной постоянной, формально повторим все предыдущие выкладки. Поскольку $\tau_{s}^{*}=\tau_{s}^{*}(\theta)=\tau_{s}^{*}(\rho)$, подставив в (13) $B^{*}$ вместо $B$, получим в неявном виде уравнение для определения плотности на ударной волне. При этом если двигаться по координате $z$ с малым шагом $\Delta h$, то распределение плотности можно на каждом шаге считать линейным и тогда выражение $\int_{0}^{z} \tau_{s}^{*} d z$ интегрируется в квадратурах. При отражении волны процедура расчета будет аналогична описанной ранее для случая без трения, только вместо уравнения (8) используем уравнение (14).

Рассмотрим случай, когда начальная плотность распределена неравномерно по высоте заготовки. В этом случае в правой части выражения (14) плотность $\rho$ должна быть внесена под знак интеграла:

$$
\sigma_{z z}-\frac{2 f}{R} \int_{0}^{z} \tau_{s}^{*} d z=\frac{\partial v_{z}}{\partial t} \int_{0}^{z} \rho d z-p(t)
$$

Уравнение (10) в этом случае примет вид:

$$
A^{*} v^{\prime}=-\{\varphi(t) v\}^{\prime}+B^{*}
$$

где $A^{*}=A-\left(\Delta \rho / \rho_{0}\right) \varphi(t), \quad \Delta \rho=\langle\rho\rangle-\rho_{0}$.

Задав малый шаг $\Delta h$, повторим выкладки, подставляя вместо $A$ величину $A^{*}$. Отсюда можно определить $\langle\rho\rangle$ и затем $\rho$ по формуле (13).

Достоверность модели также как и ранее, проверена путем сравнения данных расчета с результатами натурных испытаний [57].

Характер изменения средней остаточной пористости заготовки в зависимости от отношения текущей $v$ и начальной $v_{0}$ массовой скорости инструмента для различных значений $v_{0}$ и конечной остаточной пористости $\theta=0,01$ представлен на рис. 4. Можно видеть, что независимо от начальной скорости все кривые носят качественно схожий характер. До значения пористости $\theta \approx 0,1$ зависимость близка к линейной, затем отношение $v / v_{0}$ начинает резко уменьшаться. Очевидно, это связано с тем, что при малой пористости сопротивление порошкового материала необратимому сжатию резко возрастает.

Распределение пористости по высоте заготовки существенным образом зависит от начальной скорости и массы инструмента. Если инструментом, передающим давление, является массивный ударник и начальная скорость мала, плотность по высоте распределяется практически равномерно. Величину $A /(A+\varphi(t))$ можно представить в виде $M_{u} /\left(M_{u}+m(t)\right)$, где $m(t)$ - масса части заготовки между ударником и фронтом волны. Поскольку $M_{u}>>m(t)$, скорость меняется почти линейно, разница в плотности между верхним слоем порошка (область контакта с ударником) и нижней (контакт с дном контейнера) незначительна. Отраженная от донной части контейнера волна является волной сжатия, приводящей к дополнительному уплотнению заготовки, при ее движении в сторону ударника разница между плотностями верхней и нижней частями заготовки практически исчезает. Затем происходит отражение этой волны от массивного ударника и т. д. При импульсном прессовании массивным ударником, в отличие от статического, силы трения практически не меняют характер 
изменения плотности по высоте, приводя только к увеличению остаточной пористости, величина которой существенно зависит от отношения $h_{0} / R$.

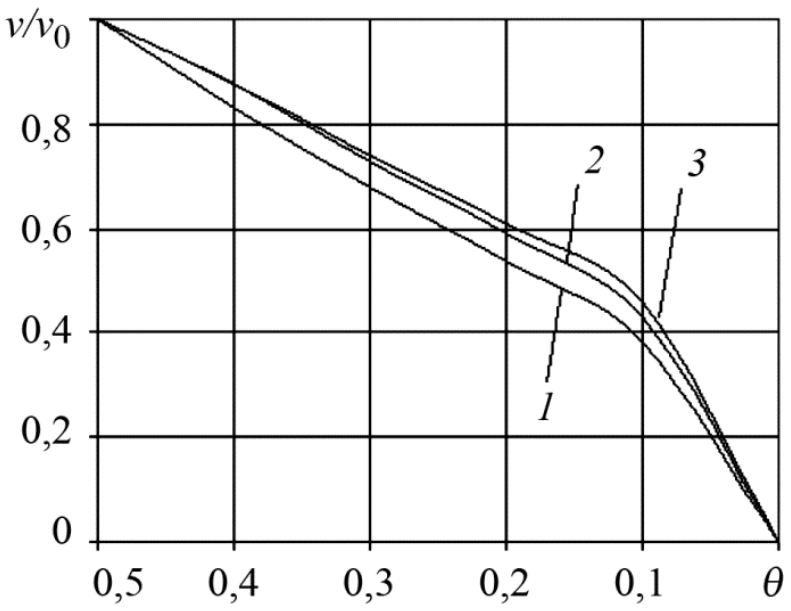

Рис. 4. Зависимость остаточной пористости заготовки от отношения текущей и начальной скорости инструмента: $1-v_{0}=10 \mathrm{M} / \mathrm{c} ; 2-v_{0}=100 \mathrm{M} / \mathrm{c} ; 3-v_{0}=200 \mathrm{M} / \mathrm{c}$

В рамках построенной модели можно также учесть скорость распространения ударных волн в порошковом материале [58].

После преобразований для скорости пластической волны имеем:

$$
\varphi^{\prime}(t)=\varphi^{\prime}(0) \frac{(A+\varphi(t))^{2}}{A^{2}}=\left(\frac{K_{M} h_{0}+z}{K_{M} h_{0}}\right)^{2} .
$$

Компонента $\sigma_{z z}$ тензора напряжений имеет вид [59]:

$$
\sigma_{z z}=-\sqrt{\left(\sigma_{s}^{*}\right)^{2}+4\left(\tau_{s}^{*}\right)^{2} / 3}
$$

Исключив из второй формулы (9) скорость $\varphi^{\prime}(t)$ и подставляя в полученное выражение формулу (18) получим:

$$
\frac{1}{\sqrt{3}}\left[\sqrt{3\left(\sigma_{s}^{*}\left(\rho_{0}\right)\right)^{2}+4\left(\tau_{s}^{*}\left(\rho_{0}\right)\right)^{2}}-\sqrt{3\left(\sigma_{s}^{*}(\rho)\right)^{2}+4\left(\tau_{s}^{*}(\rho)\right)^{2}}\right]=v^{2} \frac{\rho_{0}}{\left(1-\rho_{0} / \rho\right)} .
$$

Последнее соотношение должно выполняться на ударной волне в любой момент времени, в том числе и сколь угодно близкий к начальному. Подставив в (19) значение $v=v_{0}$, определим плотность $\rho$ в начальный момент времени, а из первой формулы в (9) начальную скорость пластической ударной волны $\varphi^{\prime}(0)$ :

$$
\varphi^{\prime}(0)=\frac{v}{\left(1-\rho_{0} / \rho\right)}=\frac{\left(1-\theta_{0}\right)+\Delta \theta}{\Delta \theta},
$$

где $\Delta \theta$ - уменьшение пористости заготовки при прохождении фронта волны.

По описанной методике выполнены расчеты процесса динамического прессования при отношении масс инструмента и заготовки $K_{\mu}=10^{2} \div 10^{4}$ (или $\lg K_{M}=2,0 \div 4,0$ ). Из фор- 
мулы (4) следует, что в случае, когда масса инструмента значительно превышает массу заготовки $\left(K_{м}>>1\right)$, скорость волны с течением времени меняется незначительно, поэтому при анализе результатов ограничимся величиной $\varphi^{\prime}(0)$.

Начальную скорость инструмента $v_{0}$ выбирали из условия достижения величины остаточной пористости $\theta=0,1$ и $\theta=0,01$. Начальная пористость $\theta_{0}=0,5$. Материал некомпактный титан. В формулах (5) приняты следующие значения параметров: $K_{1}=K_{2}=1,0$; $\eta=1, \varsigma=2 / 3$, что соответствует порам изометрической формы [55].

На рис. 5 представлены результаты расчета начальных скоростей инструмента $v_{0}$ и ударной волны $\varphi^{\prime}(0)$ при различной остаточной пористости $\theta$ в зависимости от $\lg K_{\mu}$. Можно отметить, что зависимости скоростей $v_{0}$ и $\varphi^{\prime}(0)$ от $K_{\mu}$ при различных $\theta$ носят схожий характер. С уменьшением величины $K_{\mu}$ значения $v_{0}$ и $\varphi^{\prime}(0)$ возрастают. При этом численно зависимость $v_{0}$ от $K_{\mu}$, очевидно, определяется величиной сообщаемой заготовке кинетической энергии $E=M_{u}\left(v_{0}\right)^{2} / 2$ (рис. 5 a). Как показано в работе [53] значение $E$, необходимое для получения заготовки с одной и той же остаточной пористостью слабо меняется в диапазоне $v_{0}=7,5 \div 120 \mathrm{~m} / \mathrm{c}$ (при прочих равных условиях).

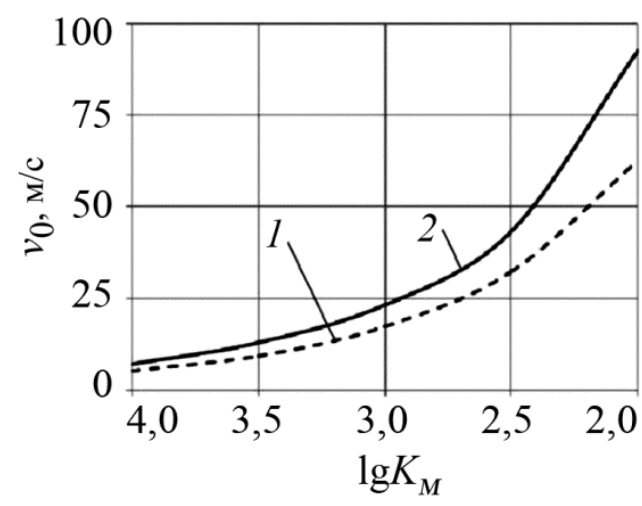

$a$

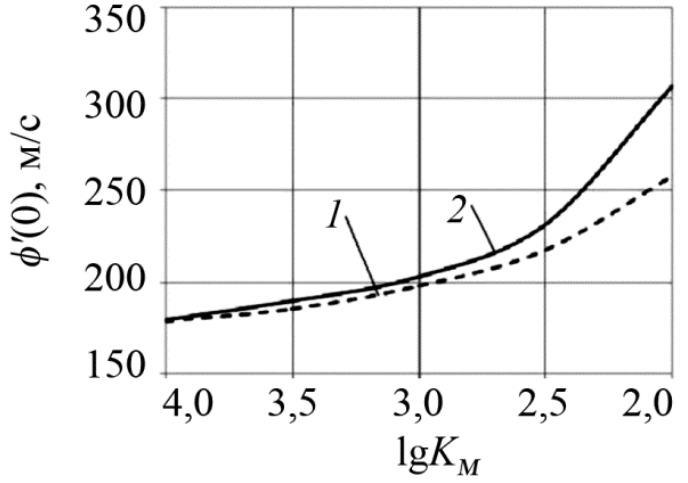

$\sigma$

Рис. 5. Зависимость начальной скорости инструмента $(a)$ и ударной волны $(б)$ от $K_{\mu}$ и $\theta$ :

$$
1-\theta=0,1 ; 2-\theta=0,01
$$

Заметим, что при одних и тех же $K_{\mu}$ значение $v_{0}$, необходимое для достижения пористости $\theta=0,01$, превышает аналогичное значение $v_{0}$ для $\theta=0,1$ в $1,35-1,4$ раза практически независимо от величины $K_{м}$. Очевидно, это связано с увеличением энергии деформирования, необходимой для достижения пористости $\theta=0,01$ вместо $\theta=0,1$ [53].

Аналогичные значения скорости ударной волны отличаются только в 1,02-1,10 раза, возрастая с уменьшением $K_{м}$. Для того чтобы объяснить указанное обстоятельство, в соответствии с работой [57] рассмотрим, как меняется характер процесса уплотнения порошка в зависимости от $K_{M}$.

Если начальная скорость ударника мала $\left(K_{\mu}\right.$ порядка $\left.5 \times 10^{3} \div 10^{4}\right)$, при прохождении по порошку волны сжатия плотность по высоте меняется мало и распределяется практически равномерно (рис. 5 a). Отраженная от донной части контейнера волна является волной сжатия, приводящей к дополнительному уплотнению заготовки. Затем происходит отражение 
этой волны от массивного ударника и т.д. (процесс повторяется многократно). При этом уменьшение пористости в начальный момент прохождения ударной волны составляет, $\Delta \theta=0,015 \div 0,05$, если остаточная пористость $\theta=0,1$ и $\Delta \theta=0,02 \div 0,065$ при $\theta=0,01$ (в зависимости от $K_{\mu}$ ). Легко видеть, что увеличение скорости $v_{0}$ в 1,35-1,4 раза приводит практически к такому же увеличению выражения $\left[\left(1-\theta_{0}\right)+\Delta \theta\right] / \Delta \theta$, поэтому в соответствии с формулой (7) величина начальной скорости ударной волны $\varphi(0)$ практически не меняется для различных значений остаточной пористости.

С уменьшением массы инструмента и, соответственно, с увеличением $v_{0}$ изменение пористости в начальный момент прохождения ударной волны составляет $\Delta \theta=0,09 \div 0,16$ и $\Delta \theta=0,13 \div 0,22$ для случаев $\theta=0,1$ и $\theta=0,01$ соответственно, при этом различие между скоростями инструмента остается прежним, т. е. в $1,35-1,4$ раза, а выражение $\left[\left(1-\theta_{0}\right)+\Delta \theta\right] / \Delta \theta$ возрастает в меньшей степени (формула (7)), что и объясняет полученный результат.

Зависимость отношения $\varphi^{\prime}(0) / v_{0}$ от величины $K_{м}$ показана на рис. 6. Как указано в работе [5], в достаточно широком диапазоне амплитуд связь между скоростью фронта ударной волны и скоростью инструмента может быть записана в виде:

$$
\varphi^{\prime}(t)=C+D v
$$

где $C, D-$ коэффициенты.

В работе [1] на основе результатов экспериментов по прессованию пористого титана и аппроксимации результатов получено: $C=100 \mathrm{~m} / \mathrm{c}, D=1,44$.

Данные, представленные на рис. 5-6, также могут быть хорошо аппроксимированы зависимостью вида (8) при следующих значениях коэффициентов: $C=170$ м/с и $D=1,45$. При этом различие между результатами, представленными на рис. 5-6 и полученными расчетным путем, по формуле вида (8), составляет менее $0,5 \%$.

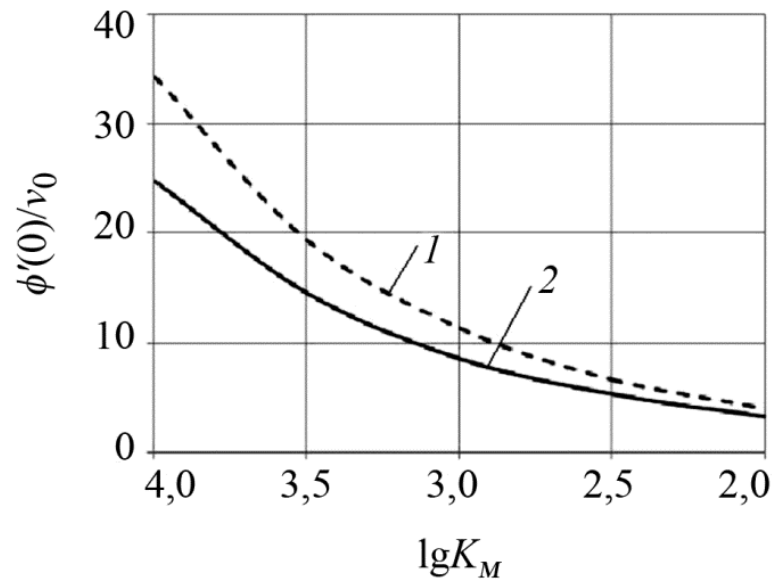

Рис. 6. Зависимость отношения скоростей $\varphi^{\prime}(0) / v_{0}$ от $K_{м}$ и $\theta: 1-\theta=0,1 ; 2-\theta=0,01$

Различие в значениях коэффициента $C$, полученных в работе [1] и данной статье может быть вызвано, прежде всего, тем, что в [1] приведены результаты экспериментальных исследований, полученные по схеме сжатия «бегущей» ударной волной (в отличие от схемы на рис. 1 фронт волны не перпендикулярен к границе раздела «инструмент-порошок»). При этом результаты получены при массовых скоростях $v_{0}=0,65 \div 1,3$ км/с, т. е. значительно превышающих значения, полученные в данной работе (рис. 5). Частично расхождение в значениях коэффициента $C$ также может быть связано с тем обстоятельством, что авторами [1] 
скорость волны определялась на основе экспериментальных данных, путем анализа рентгенограмм и выбора подходящих интерполяционных функций для вычисления скорости ударной волны и массовой скорости, т. е. с некоторой погрешностью.

С учетом вышеизложенного можно считать, что результаты расчета скорости ударной волны соответствуют реальной картине, возникающей при динамическом прессовании порошкового материала в рассматриваемом диапазоне изменения параметров $K_{\mu}$ и $v_{0}$.

На рис. 7 представлены результаты расчета давления $p$ на фронте ударной волны в начальный момент времени. В качестве $p$ в данном случае рассматривается разность между давлением за фронтом пластической ударной волны и давлением (напряжением), соответствующим переходу среды в пластическое состояние (аналогично избыточному давлению в газовой динамике). Его величина определяется с помощью второй из формул (1):

$$
p=\rho_{0} \varphi^{\prime}(t) v .
$$

Приведены зависимости давления $p$ от величины $K_{м}$ для случаев $\theta=0,1$ и $\theta=0,01$ а также его зависимость от начальной скорости ударника $v_{0}$. Видим, что максимальное значение величины $p$ в исследуемом диапазоне изменения параметров составляет немного более 60 МПа. В работе [1] в результате обработки экспериментальных данных для определения скорости ударной волны (см. выше) с использованием закона сохранения импульса построена кривая «давление-массовая скорость» для пористого титана при $v_{0}=0,65 \div 1,3 \kappa \mu / c$, причем в качестве давления на фронте ударной волны рассматривалась именно величина $p$ (формула (9)). Экстраполяция указанной кривой на диапазон $v_{0}=0 \div 0,65$ км/с [1] приводит к результатам, количественно соответствующим рис. 7 б.

Полное давление на заготовку в момент начала прессования $p_{n}$ определим по формуле:

$$
p_{n}=p+\left|\sigma_{z z}\left(\rho_{0}\right)\right| \text {. }
$$

В частности при начальной пористости $\theta_{0}=0,5$ принятой для расчетов с учетом формул (5) и значений, входящих в них коэффициентов, имеем $\sigma_{z z}\left(\rho_{0}\right)=0,99 \tau \approx \approx 140$ МПа.

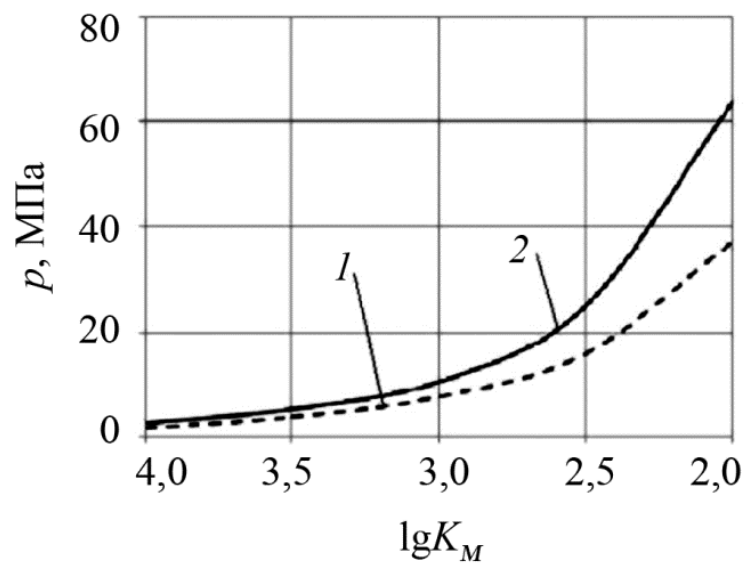

$a$

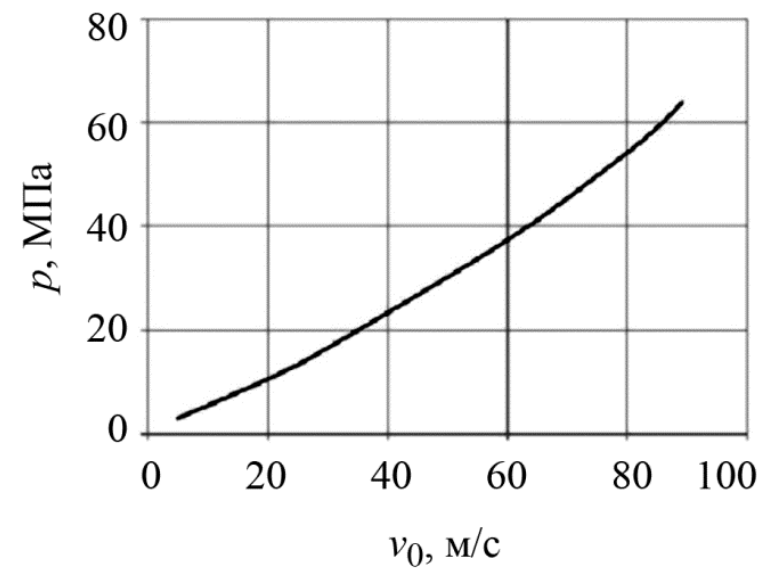

6

Рис. 7. Зависимость давления на фронте волны от $K_{м}$ и $\theta(a)$ и $v_{0}(б)$ :

$$
1-\theta=0,1 ; 2-\theta=0,01
$$




\section{4. Компьютерное моделирование процессов динамического прессования некомпактных материалов}

Для компьютерного моделирования процессов динамического прессования некомпактных материалов разработан программный комплекс DSPressing (Dynamic Shock-wave Pressing), реализованный в среде программирования Microsoft Visual C++. Приведем краткое описание пакета на примере модуля, реализующего процесс прессования в замкнутой цилиндрической пресс-форме. Головное окно программы показано на рис. 8. Оно обеспечивает доступ к информационному и расчетному блокам программы.

На рис. 9 представлено информационное окно программы, позволяющее обеспечить доступ к справочным материалам. С помощью кнопки «Справка» можно ознакомиться с математической постановкой задачи динамического прессования (файл в формате Microsoft Word). Работу других двух кнопок иллюстрируют рис. 10 и 11. На рис. 10 представлено окно программы, иллюстрирующее схему процесса динамического прессования, на рис. 11 - пример экранного меню с элементами панели управления.

Указанное меню используется в рабочем окне программы, представленном на рис. 12. Оно содержит 3 области. В основной части представлена графическая модель процесса, область слева предназначена для вывода на экран графиков. Верхний график показывает изменение средней остаточной пористости заготовки в зависимости от скорости инструмента. На нижнем графике показано распределение остаточной пористости по высоте заготовки. В нижней части окна приведены значения исходных данных. Пользователь может изменять размеры областей или их отключать. Предусмотрено управление цветом фона каждой области и графиков, а также инструмента и заготовки (рис. 12). Для ввода исходных данных в программе имеются отдельные окна, вызов которых осуществляется посредством меню.

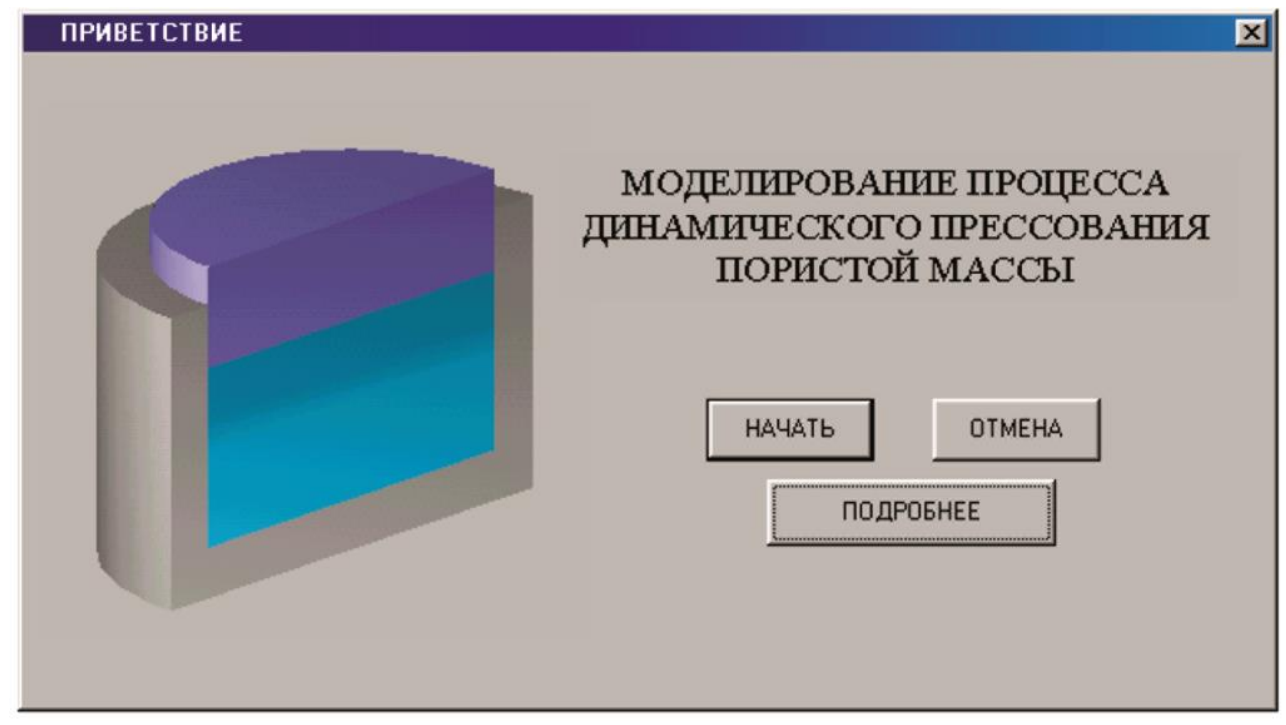

Рис. 8. Головное окно программы DSPressing 


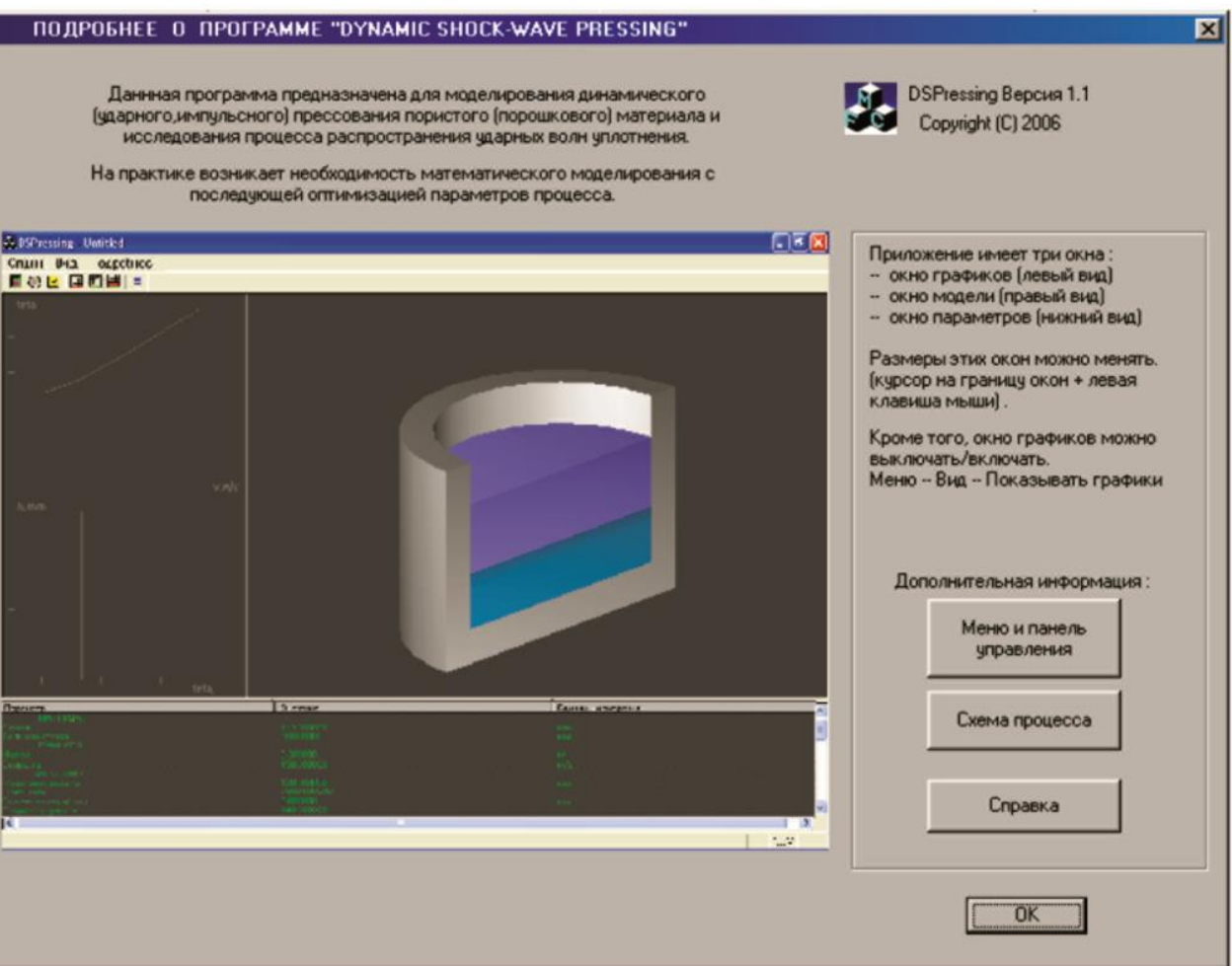

Рис. 9. Информационное окно программы DSPressing

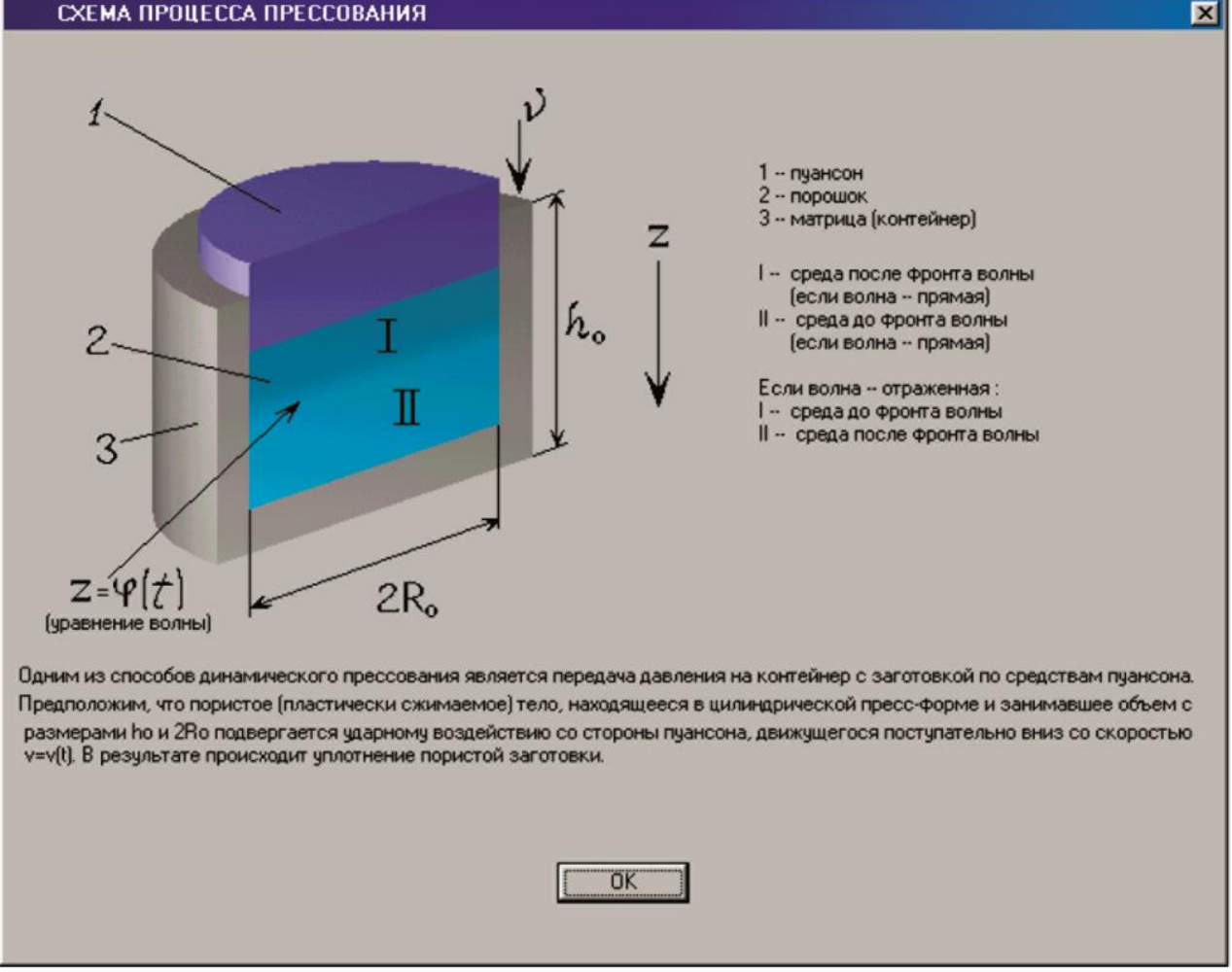

Рис. 10. Описание схемы процесса 


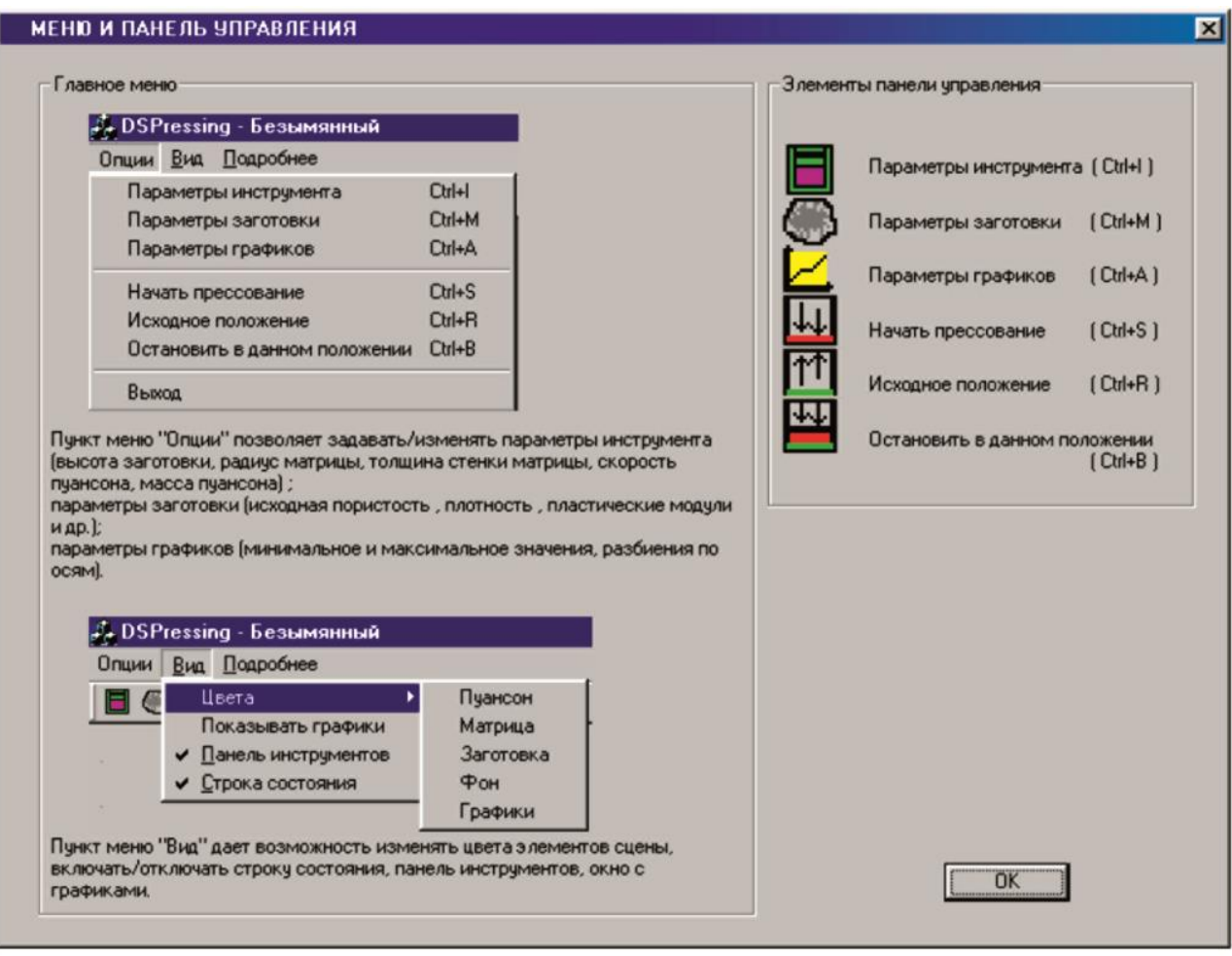

Рис. 11. Описание меню и панели управления программы DSPressing

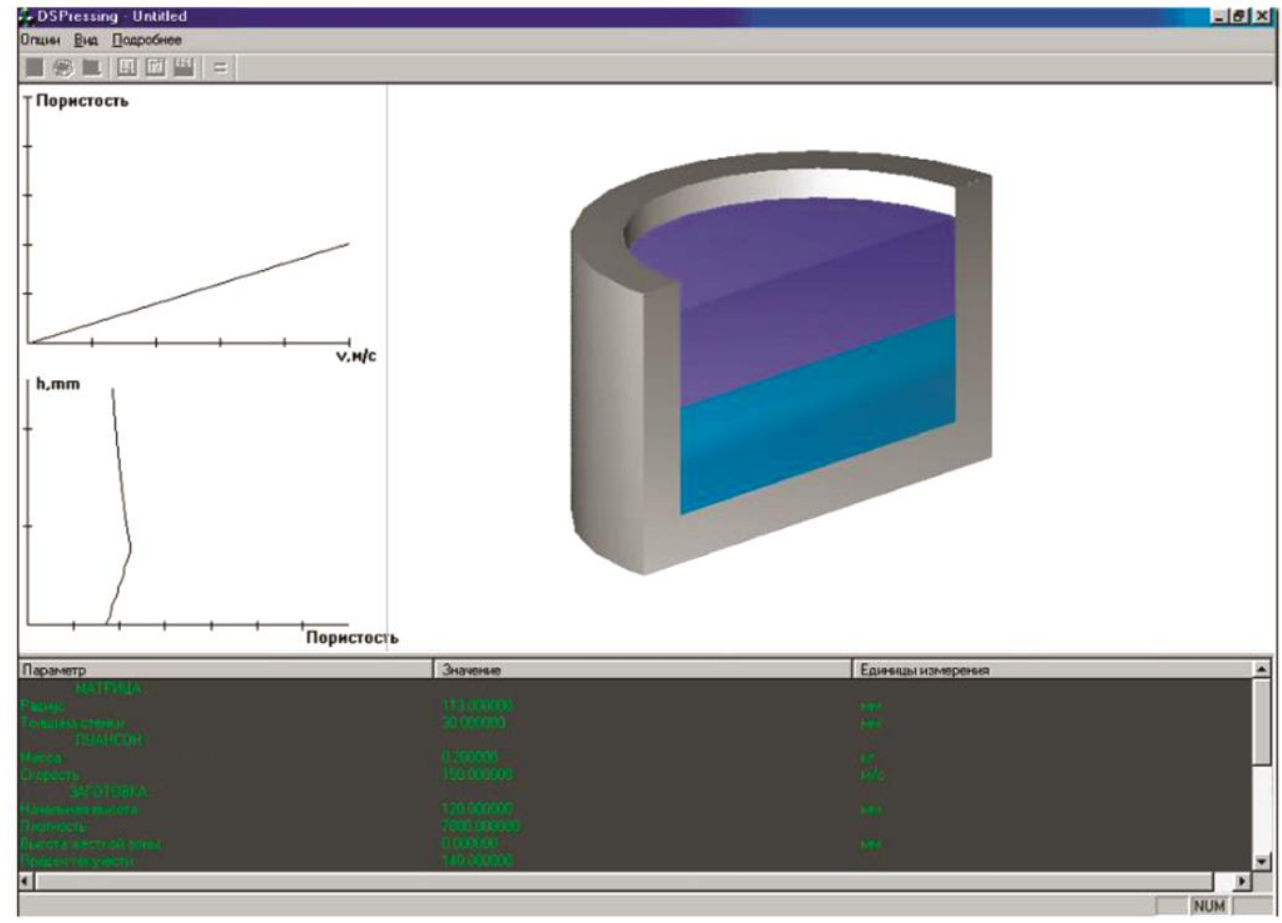

Рис. 12. Рабочее окно программы DSPressing

Программа позволяет выполнить расчет с одновременным замедленным просмотром процесса распространения ударной волны, графически отображает изменение во времени параметров процесса (скорость волны, изменение плотности на ее фронте; рис. 12). 


\section{3. Ударное выдавливание заготовки через коническую матрицу}

\section{1. Ударное выдавливание несжимаемого материала}

Раздел посвящен исследованию энергосиловых параметров процесса ударного выдавливания через коническую матрицу. Ставится задача определения минимально необходимой начальной скорости инструмента, для которой при заданном соотношении масс заготовки и инструмента может быть осуществлен процесс. При этом на величину энергии деформирования влияет трение заготовки о стенки контейнера и вытяжка. Для решения задачи используем подход работы [61]. Запишем уравнение баланса энергии:

$$
\int_{\Omega}\left[\sigma_{i j} \xi_{i j}+\rho w v\right] d \Omega-\left.\int_{S_{S}}\left(\sigma_{r z} v_{z}\right)\right|_{r=R} d S-\left.\int_{S_{V}}\left(\sigma_{z z} v_{z}\right)\right|_{z=-L} d S=0 .
$$

Очевидно, формула (24) справедлива в любой фиксированный момент времени $t$.

Для определения величин, входящих в два первых интеграла, используем решение, полученное в работе [61]. Схема процесса ударного выдавливания представлена на рис. 13.

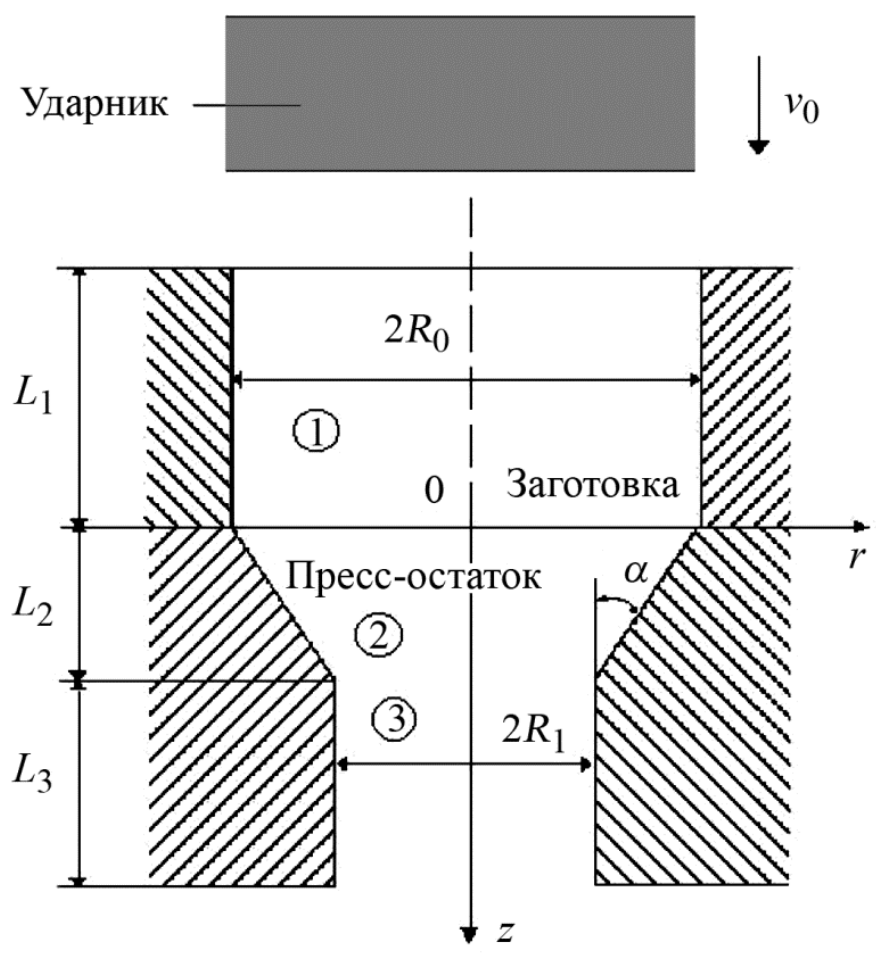

Рис. 13. Схема процесса ударного выдавливания

В области «2» деформируемые частицы при выдавливании пресс-остатка испытывают сжатие в направлении координат $\varphi, r$ и растяжение вдоль оси $z$. В областях «1» и «3» материал движется вдоль оси $z$ как абсолютно твердое тело. На поверхностях стыка областей «1»- «2» и «2»- «3» возможен разрыв касательной компоненты вектора скорости. Принятые допущения позволяют записать поле скоростей и компоненты тензора скоростей деформации $\xi_{i j}$ в следующем виде:

для области 1:

$$
v_{1}^{(\varphi)}=0 ; \quad v_{1}^{(r)}=0 ; \quad v_{1}^{(z)}=v_{0} ; \quad \xi_{i j}^{(1)}=0 \quad(i, j=r, \varphi, z) ; \quad H^{(1)}=0 ;
$$


для области 2:

$$
\begin{aligned}
& v_{2}^{(r)}=-v_{1} \frac{R_{1}^{2}}{R_{z}^{3}} \operatorname{rtg} \alpha ; \quad v_{2}^{(z)}=v_{1} \frac{R_{1}^{2}}{R_{z}^{2}} ; \quad R_{z}=R_{0}-z \operatorname{tg} \alpha ; \\
& \xi_{r \varphi}^{(2)}=\xi_{\varphi z}^{(2)}=0 ; \quad \xi_{r z}^{(2)}=-\frac{3}{2} v_{1} \frac{R_{1}^{2}}{R_{z}^{4}} \operatorname{rtg}^{2} \alpha ; \quad \xi_{r r}^{(2)}=\xi_{\varphi \varphi}^{(2)}=-v_{1} \frac{R_{1}^{2}}{R_{z}^{3}} \operatorname{tg} \alpha ; \\
& \xi_{z z}^{(2)}=2 v_{1} \frac{R_{1}^{2}}{R_{z}^{3}} \operatorname{tg} \alpha ; \quad \mathrm{H}^{(2)}=2 \sqrt{3} v_{1} \operatorname{tg} \alpha \frac{R_{1}^{2}}{R_{z}^{3}} \sqrt{1+\frac{3}{4} \frac{r^{2}}{R_{z}^{2}} \operatorname{tg}^{2} \alpha ;}
\end{aligned}
$$

для области 3:

$$
v_{3}^{(\varphi)}=0 ; \quad v_{3}^{(r)}=0 ; \quad v_{3}^{(z)}=v_{3}=\mu v_{0} ; \quad \xi_{i j}^{(3)}=0 \quad(i, j=r, \varphi, z) ; \quad H^{(3)}=0 .
$$

После преобразований получаем [60]:

$$
\dot{z}^{2}=v_{0}^{2}+\frac{2 C}{B}\left(z+L_{1}\right)+2\left(\frac{A C}{B^{2}}-\frac{D}{B}\right) \ln \frac{(A-B z)}{\left(A+B L_{1}\right)},
$$

где $A=\frac{\rho}{\sqrt{3} \tau_{s}}\left\{R_{0}(\sqrt{\mu}-1)\left(\frac{\operatorname{tg} \alpha}{2}+\operatorname{ctg} \alpha\right)+\left(L_{3}-K_{\mu} L_{1}\right)\right\} ; B=\frac{\rho}{\sqrt{3} \tau_{s}} ; C=\frac{2 f}{\sqrt{3} R_{0}} ;$ $D=\frac{8}{9 \operatorname{tg}^{2} \alpha}\left[\left(1+\frac{3}{4} \operatorname{tg}^{2} \alpha\right)^{3 / 2}-1\right] \ln \mu+\frac{4}{3 \sqrt{3}} \operatorname{tg} \alpha^{\prime}+\frac{f}{\sqrt{3}}\left(\operatorname{ctg} \alpha^{\prime}+\operatorname{tg} \alpha^{\prime}\right) \ln \mu$.

Уравнение (25) не интегрируется в квадратурах. Поэтому определить зависимость $z=z(t)$ возможно только численно. Однако, формула (25) позволяет однозначно определить энергосиловые параметры процесса. Действительно, выдавливание (движение заготовки) будет происходить, пока выполняется условие $v>0$. Поскольку $v=\dot{z}$, из (25) можно найти значение координаты $z$, при котором скорость $v$ обращается в ноль, т. е. величину скорости ударника к моменту достижения им границы зон «1» и «2». Нас интересует скорость инструмента, позволяющая осуществить процесс ударного выдавливания. Принимая $z=0$, запишем уравнение (25) в следующем виде:

$$
v_{0}=\left\{-\left[\frac{2 C}{B} L_{1}+2\left(\frac{A C}{B^{2}}-\frac{D}{B}\right) \ln \left(\frac{A}{A+B L_{1}}\right)\right]\right\}^{1 / 2} .
$$

Формула (26) позволяет однозначно определить величину скорости $v_{0}=v_{0}\left(A, B, C, D, L_{1}\right)$ такую, что в момент достижения ударником границы зон «1»и «2» $\dot{z}=v=0$. Процесс выдавливания может быть осуществлен (ударник полностью пройдет зону «1») при начальной скорости $v \geq v_{0}\left(A, B, C, D, L_{1}\right)$. Таким образом, формула (26) дает возможность определить энергосиловые параметры процесса.

На рис. 14-19 представлены результаты расчета минимально необходимой скорости ударника $v_{0}$ при $L_{1}=3 R_{0}, L_{3}=0,5 R_{0}$. Механические свойства соответствуют порошку ПЖ4М2: $\rho=7800$ кг $/ \mathrm{M}^{3} ; \tau_{s}=142 \mathrm{MПа} \mathrm{[62]} \mathrm{и} \mathrm{брикету} \mathrm{из} \mathrm{титановой} \mathrm{губки.} \mathrm{Расчеты} \mathrm{выполне-}$ ны при $\alpha=15^{\circ} \div 75^{\circ}, \mu \in[6 ; 10], K_{M}=[100 ; 10000], \theta=0,01$ и различных значений безраз- 
мерного параметра, характеризующего трение $\tilde{f}=\left(f L_{1}\right) /\left(\sqrt{3} R_{0}\right) \in[0 ; 0,6]$. Видим, что минимальное значение необходимой начальной скорости ударника существенно зависит от трения. Независимо от материала и величины $K_{м}$ с увеличением трения оптимальное значение угла меняется от $\alpha \approx 25 \div 30^{\circ}$ для $\tilde{f}=0,2$ до $\alpha \approx 35 \div 40^{\circ}$ для $\tilde{f}=0,6$ [60].

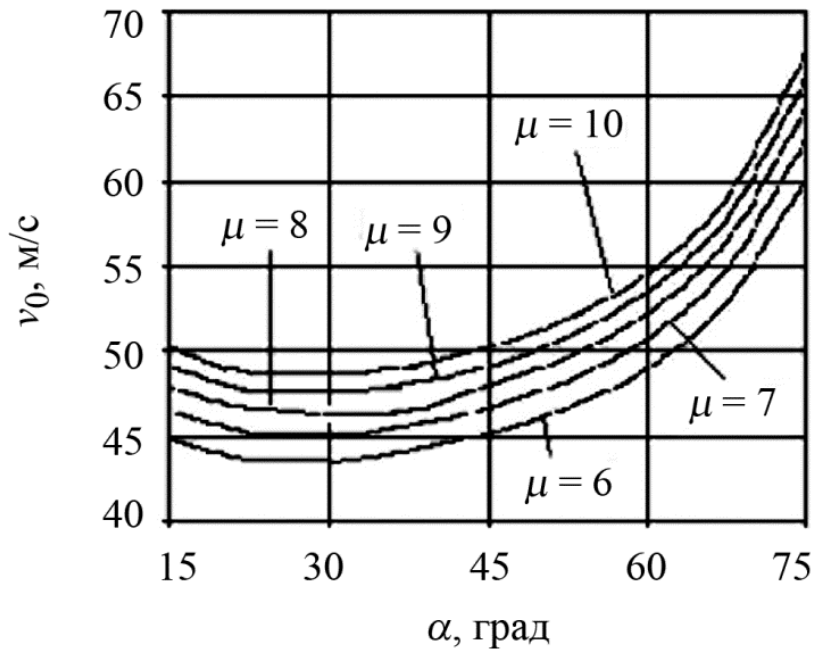

$a$

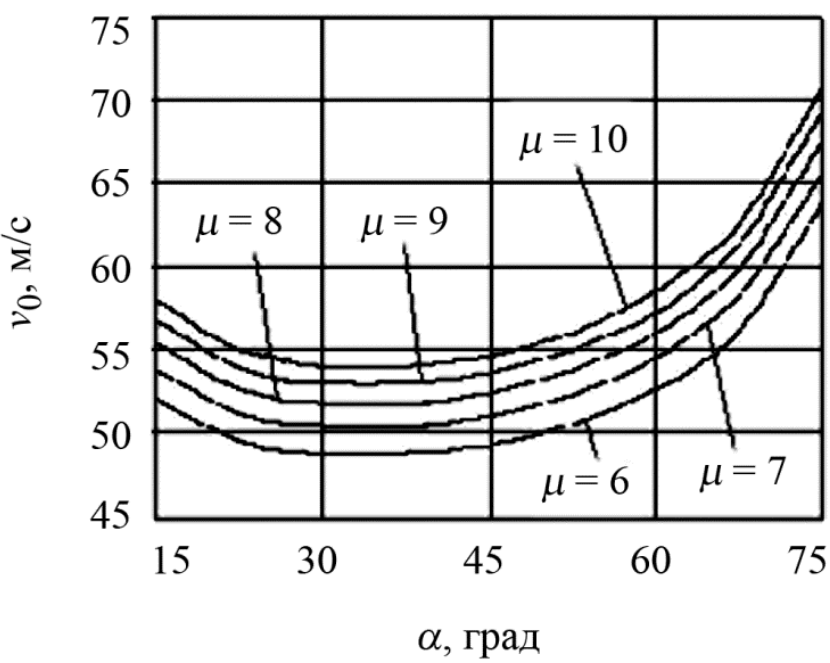

$\sigma$

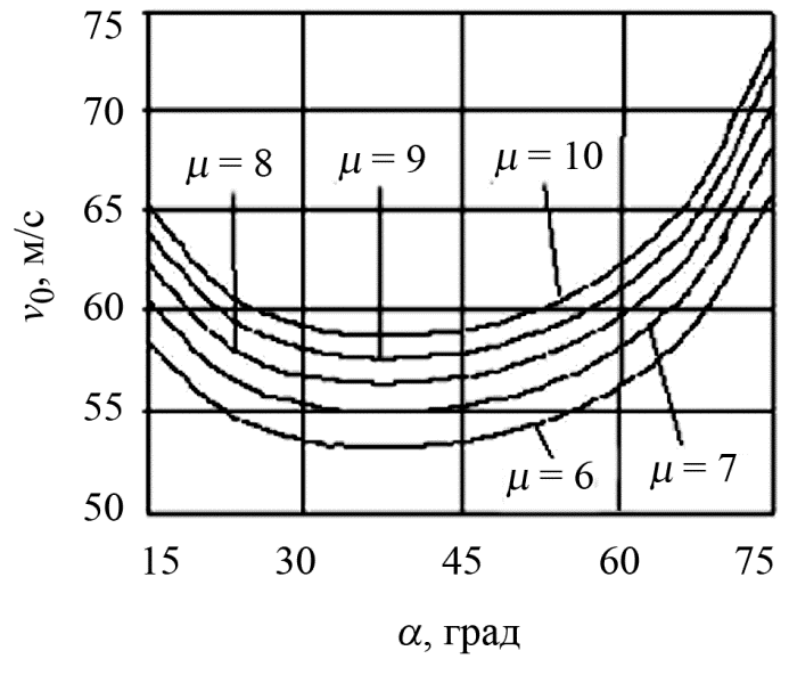

B

Рис. 14. Зависимости скорости $v_{0}$, необходимой для выдавливания прутка из порошка ПЖ4М2 от вытяжки, трения и $\alpha$ при $K_{м}=100: a-\tilde{f}=0,2 ; \sigma-\tilde{f}=0,4 ; в-\tilde{f}=0,6$ 


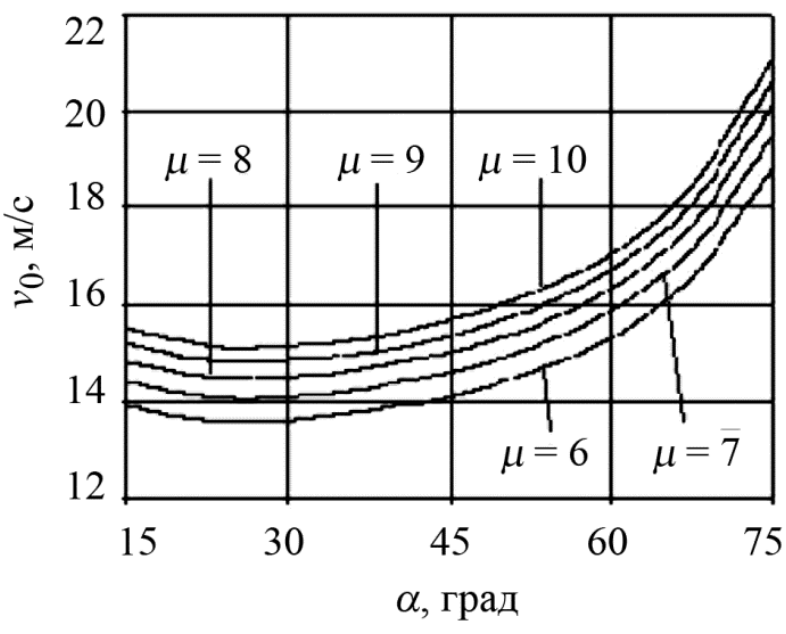

$a$

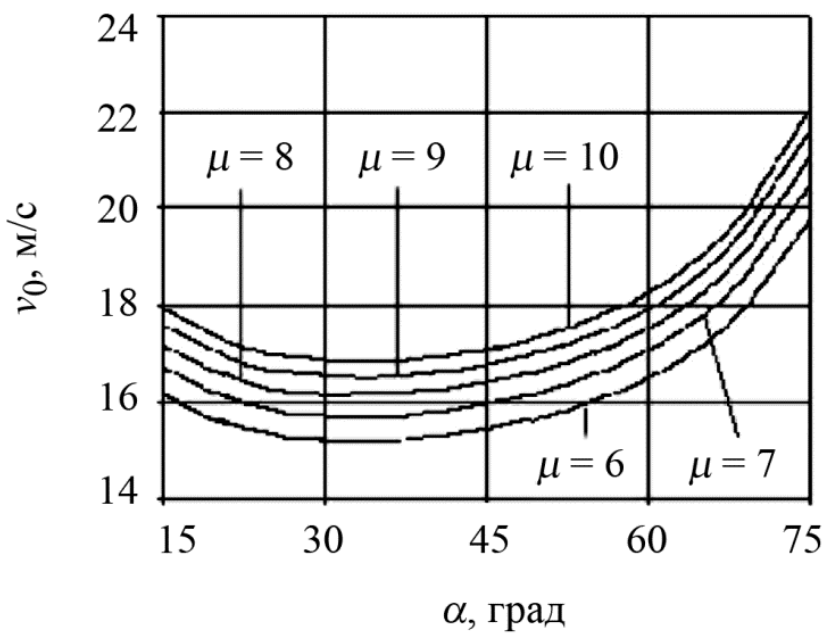

$\sigma$

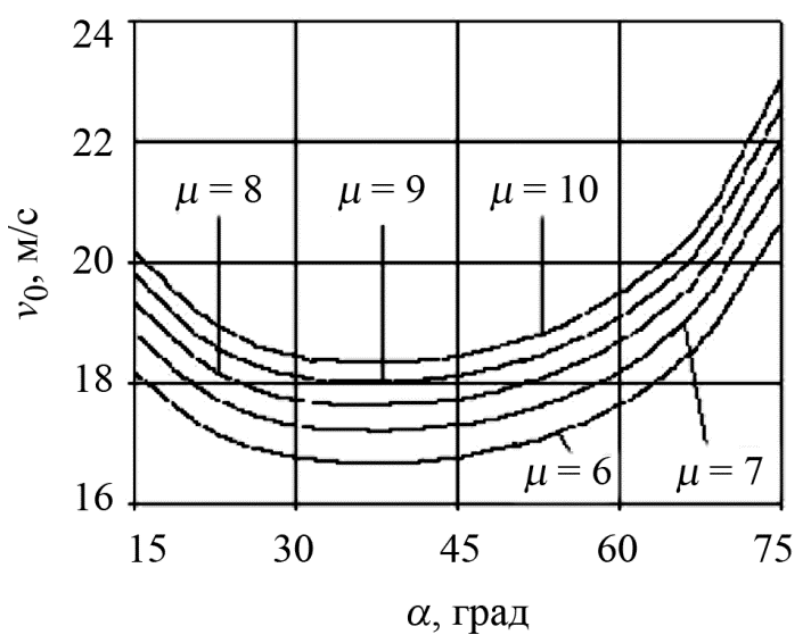

B

Рис. 15. Зависимости скорости $v_{0}$, необходимой для выдавливания прутка из порошка ПЖ4М2 от вытяжки, трения и $\alpha$ при $K_{\mu}=1000: a-\tilde{f}=0,2 ; \sigma-\tilde{f}=0,4 ; в-\tilde{f}=0,6$ 


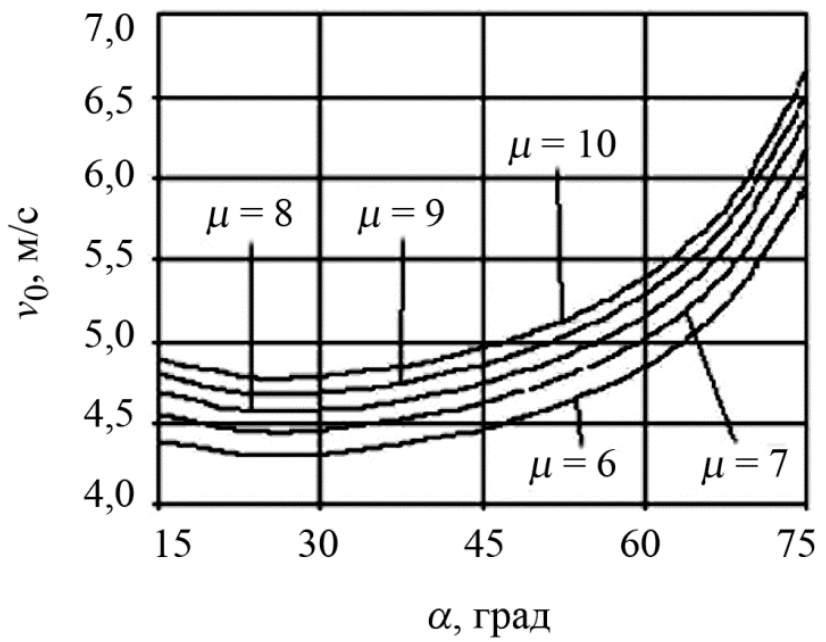

$a$

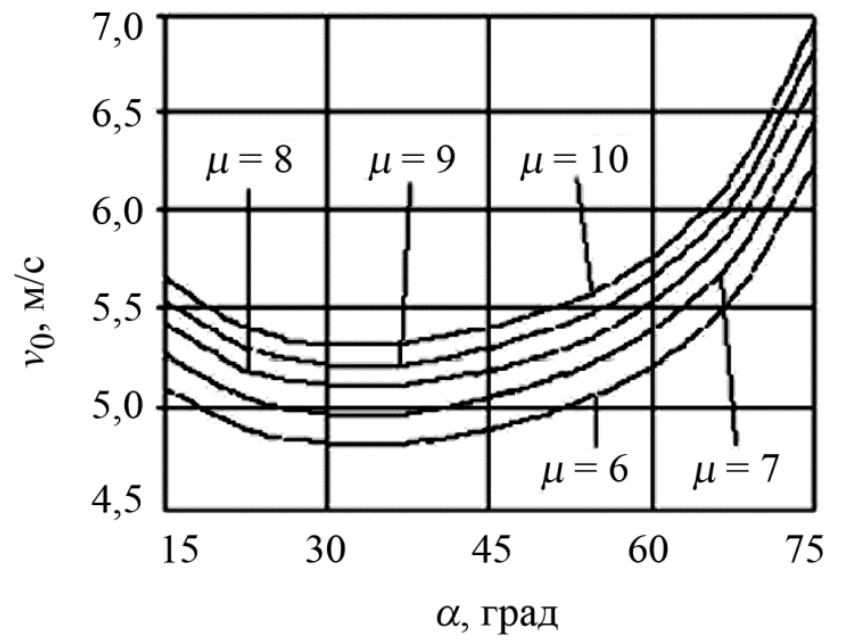

$\sigma$

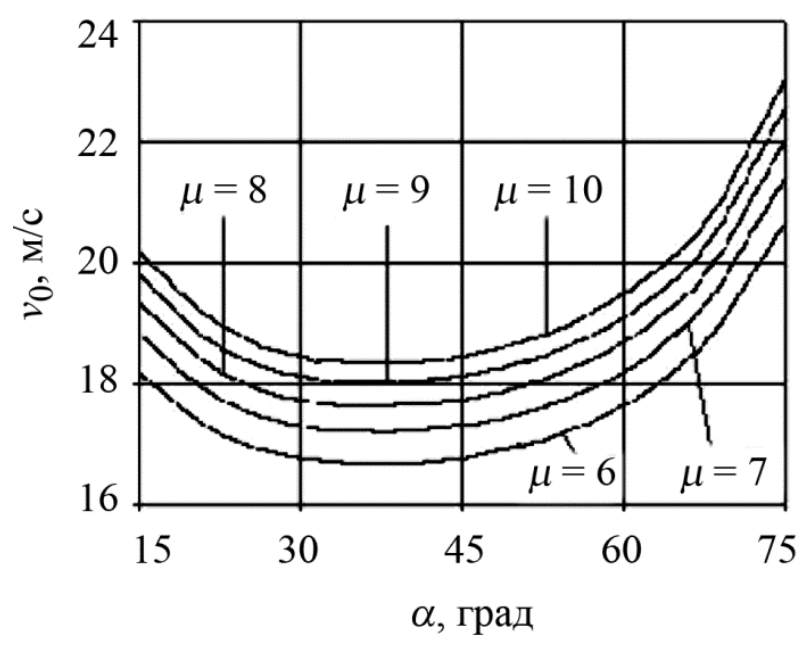

8

Рис. 16. Зависимости скорости $v_{0}$, необходимой для выдавливания прутка из порошка ПЖ4М2 от вытяжки, трения и $\alpha$ при $K_{м}=10000: a-\tilde{f}=0,2 ; \sigma-\tilde{f}=0,4 ; в-\tilde{f}=0,6$ 

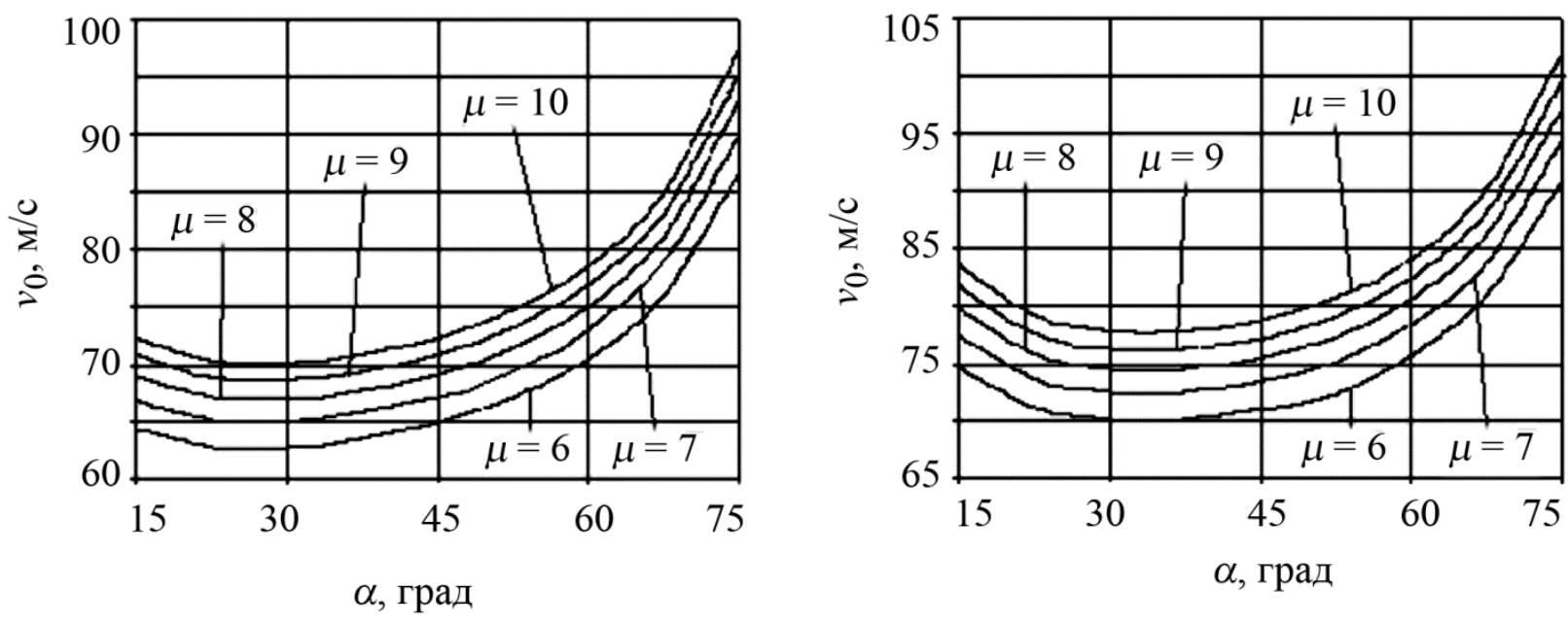

$a$

$\sigma$

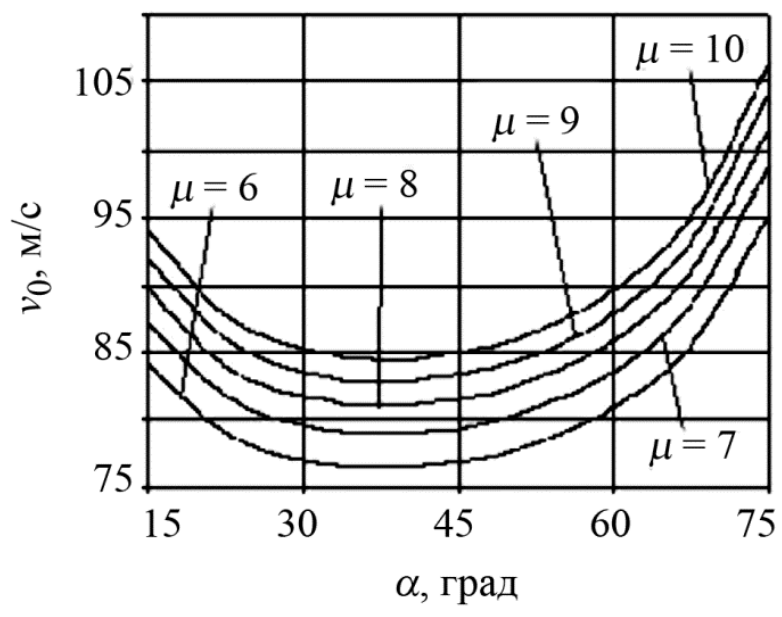

8

Рис. 17. Зависимости скорости $v_{0}$, необходимой для выдавливания прутка из некомпактного титана от вытяжки, трения и $\alpha$ при $K_{м}=100: a-\tilde{f}=0,2 ; \sigma-\tilde{f}=0,4 ; \theta-\tilde{f}=0,6$ 


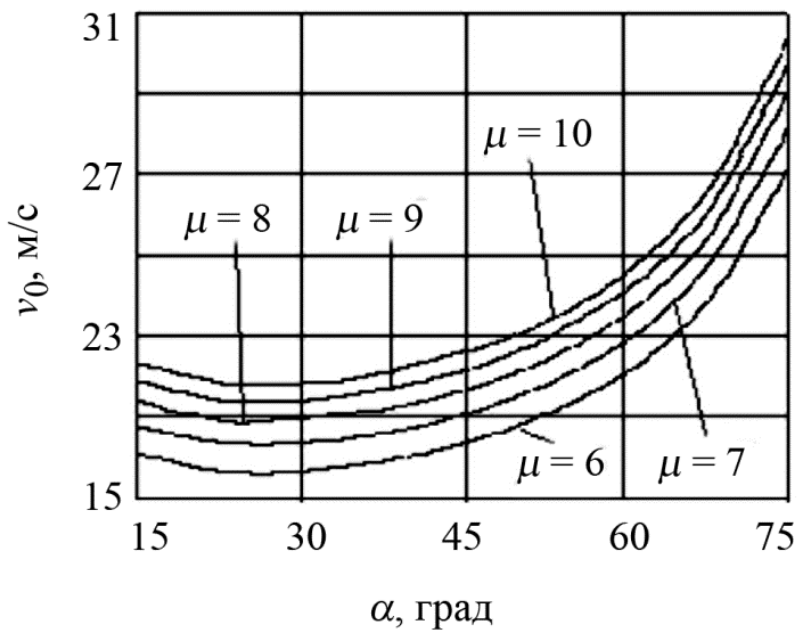

$a$

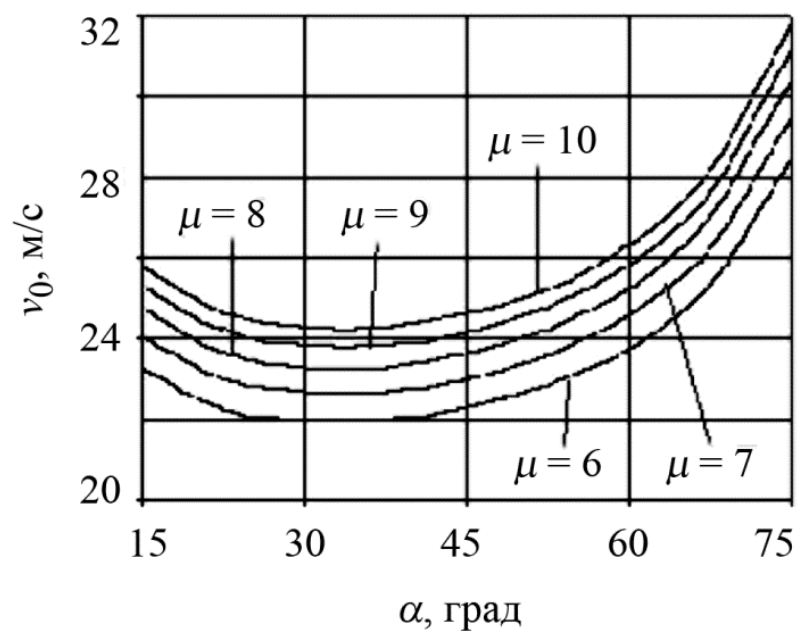

6

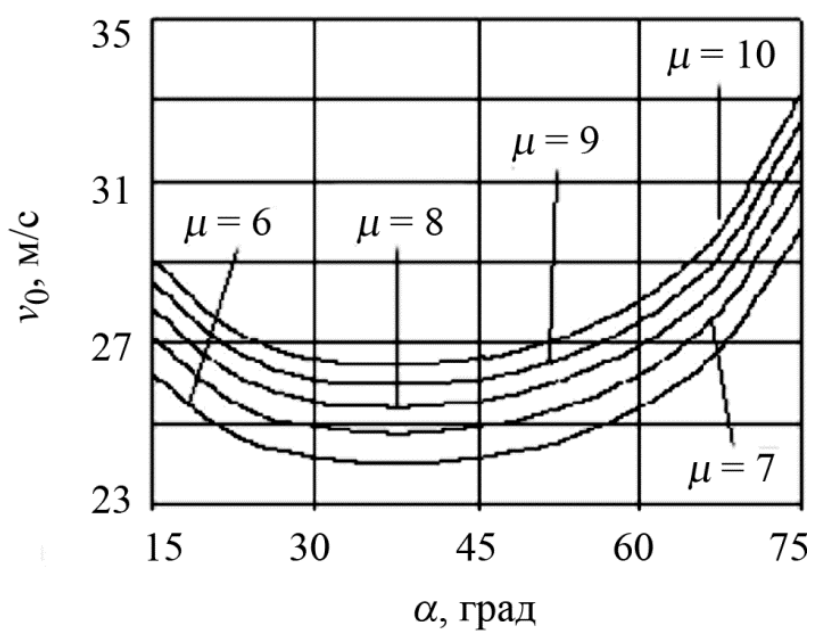

B

Рис. 18. Зависимости скорости $v_{0}$, необходимой для выдавливания прутка из некомпактного титана от вытяжки, трения и $\alpha$ при $K_{M}=1000: a-\tilde{f}=0,2 ; \sigma-\tilde{f}=0,4 ; \beta-\tilde{f}=0,6$ 

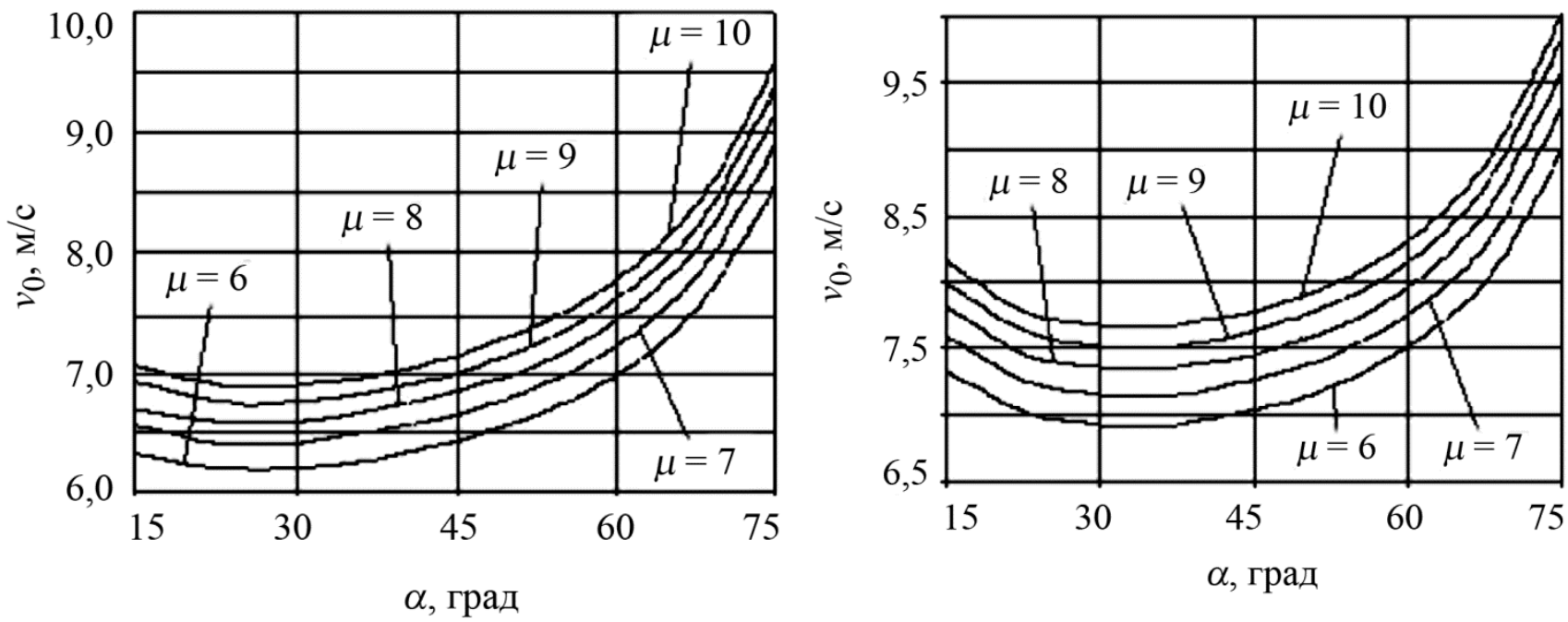

$a$

$\sigma$

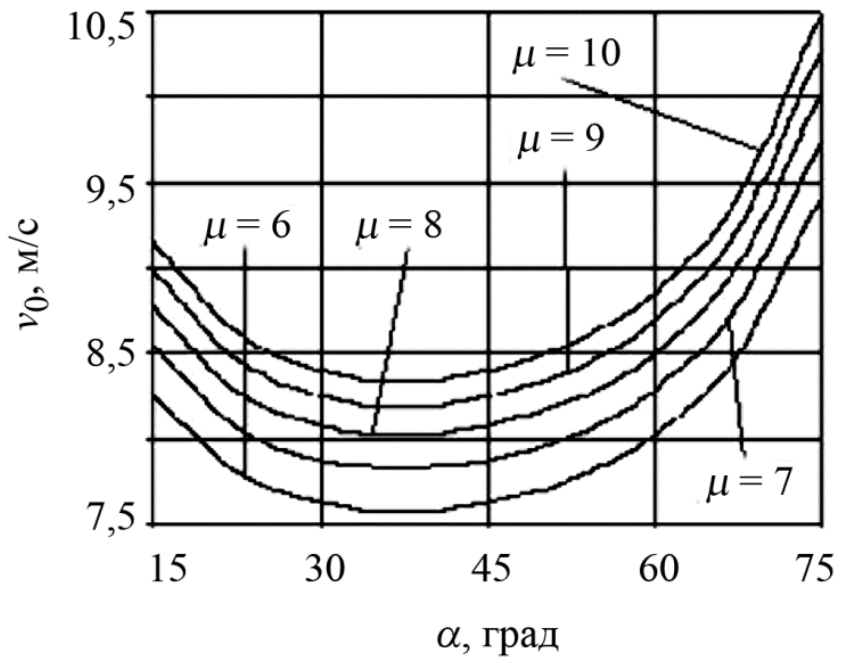

8

Рис. 19. Зависимости скорости $v_{0}$, необходимой для выдавливания прутка из некомпактного титана от вытяжки, трения и $\alpha$ при $K_{м}=10000: a-\tilde{f}=0,2 ; \sigma-\tilde{f}=0,4 ; в-\tilde{f}=0,6$

Поскольку суммарное усилие выдавливания складывается из затрат на деформацию материала в очаге деформации и потерь на трение, полученный результат обусловлен перераспределением потерь на деформацию и трение (при одной и той же вытяжке длина участка, где учитывается трение, уменьшается с ростом угла $\alpha$ ) так, чтобы сумма их была минимальна.

От вытяжки положение оптимума по скорости практически не зависит, в отличие от квазистатического случая. Действительно, в соответствии с формулами (5) и (24) давление на заготовку в данном случае линейно зависит от ускорения. Поэтому оптимальный угол определяется минимумом площади под кривой «ускорение - координата».

Данные, представленные на рис. 14-19, получены для пористости $\theta=0,01$. Однако они могут быть использованы и при других значениях пористости. Как показали расчеты, в диапазоне изменения пористости от 0,01 до $0,10-0,15$ связь $v_{0}=v_{0}(\rho)$ можно считать линейной. Тогда определить величину скорости $v_{0}$, например для заготовки пористостью $\theta=0,1$, можно по формуле: $\left.v_{0}\right|_{\theta=0,1}=\left.v_{0}\right|_{\theta=0,01} *[(1-0,1) /(1-0,01)]$, где значение «1» в правой части формулы соответствует компактному материалу. 
В заключение данного раздела заметим, что полученные результаты, касающиеся методики расчета энергосиловых параметров и характерных особенностей процесса ударного выдавливания могут быть применены как к макрооднородным металлическим материалам, так и к композитам. В последнем случае при расчетах необходимо использовать эффективные значения плотности и предела текучести материала.

\section{2. Ударное выдавливание заготовки с учетом сжимаемости материала}

Для оценки энергосиловых параметров процесса можно принять следующую приближенную схему решения [63; 64]. На первом этапе заготовка в области «1» уплотняется до плотности пресс-остатка или близкой к ней, так что в последующем разницей в плотностях можно пренебречь. При этом выдавливания не происходит. Решение этой задачи описано в разделе 2.3. Затем начинается процесс выдавливания уже при постоянной плотности в соответствии со схемой, описанной в разделе 3.1 .

Рассмотрим результаты расчетов по описанной выше модели. Выбраны те же геометрические параметры и материалы что и в предыдущем разделе. Трение задано в виде безразмерного параметра $\tilde{f} \in[0,2 ; 0,6]$. На рис. 20-25 приведены графики изменения скорости инструмента в зависимости от пористости пресс-остатка при значении $\tilde{f}=[0,2 ; 0,6]$ для стадии прессования в замкнутом объеме. Указанные графики совместно с данными, приведенными на рис. 14-19, позволяют определить начальную скорость инструмента, необходимую для осуществления процесса ударного выдавливания заготовки с учетом уплотнения материала в достаточно широком диапазоне изменения параметров.

Проиллюстрируем применение введенных зависимостей на конкретном примере. Пусть исходная пористость заготовки из порошка ПЖ4М2 $\theta_{0}=0,25$; пористость прессостатка $\theta=0,02$; вытяжка $\mu=9$, угол конусности $\alpha=30^{\circ} ; K_{\mu}=100 ; \tilde{f}=0,6$. Определим скорость $v_{1}$, позволяющую осуществить выдавливание. Используем кривую, соответствующую значению $\mu=9$ на рис. 14 в. Углу $\alpha=30^{\circ}$ соответствует скорость $v_{0}=58 \mathrm{~m} / \mathrm{c}$. Далее используем графики (рис. 20 в). Пористости $\theta=0,02$ и скорости $v_{0}=58 \mathrm{~m} / \mathrm{c}$ соответствует точка на второй сверху кривой. Находим на этой же кривой значение пористости $\theta=0,25$. Ему соответствует скорость $v \approx 63 \mathrm{~m} / \mathrm{c}$. Это минимальная скорость, при которой осуществимо уплотнение заготовки до пористости $\theta=0,02$ с последующим выдавливанием. 

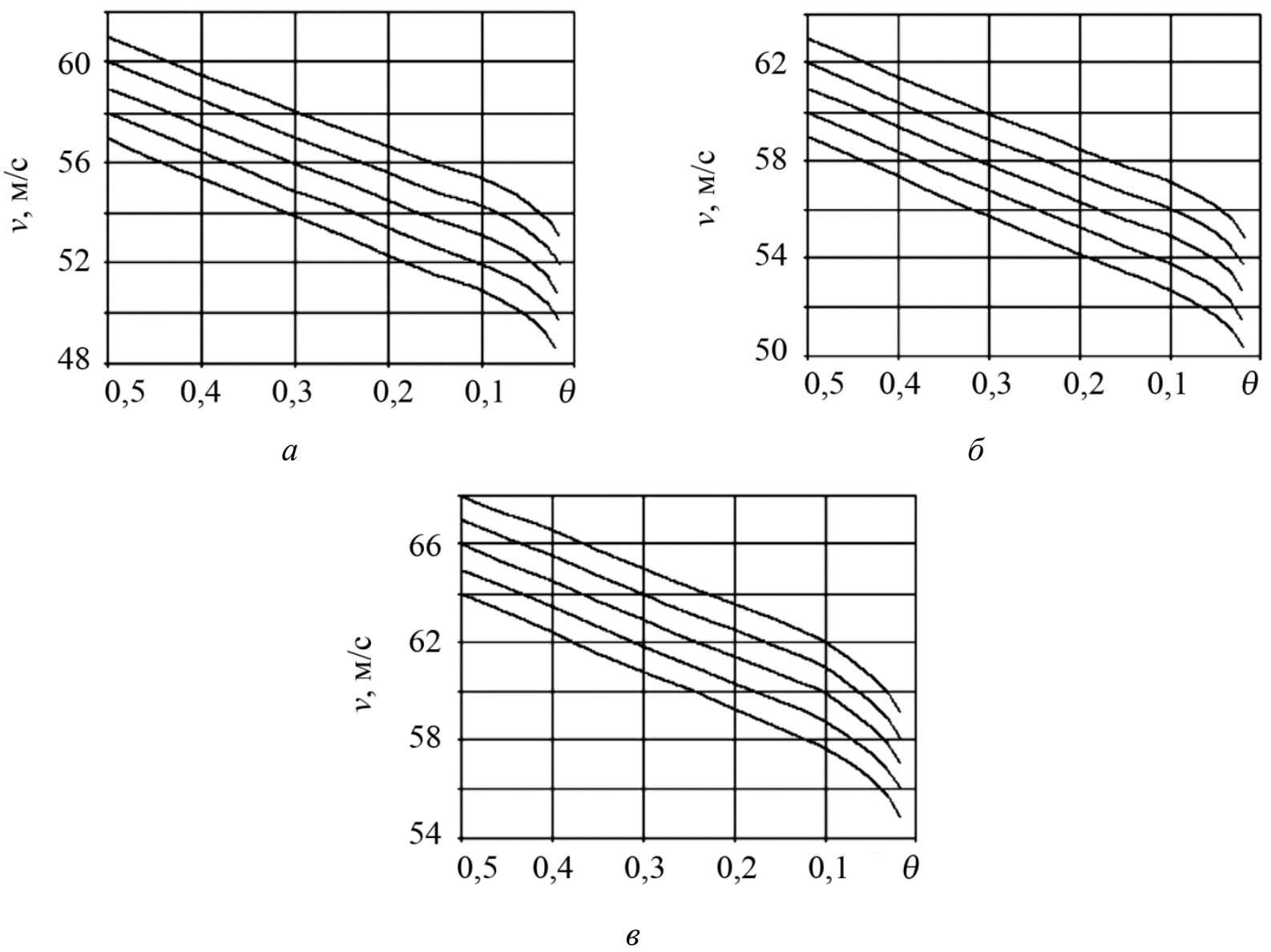

Рис. 20. Зависимость скорости инструмента от пористости при прессовании в замкнутом объеме порошка ПЖ4М2 для $K_{м}=100: a-\tilde{f}=0,2 ; \sigma-\tilde{f}=0,4 ; в-\tilde{f}=0,6$

Следует также сделать замечание относительно графиков, представленных на рис. 20-25. Данные на каждом рисунке приведены для различных значений параметра $\tilde{f}$, характеризующего трение. Можно заметить, что кривые для соответствующего материала и величины $K_{м}$ при одном и том же значении начальной скорости, соответствующей пористости $\theta=0,5$, но разных значениях $\tilde{f}$ мало отличаются друг от друга. 

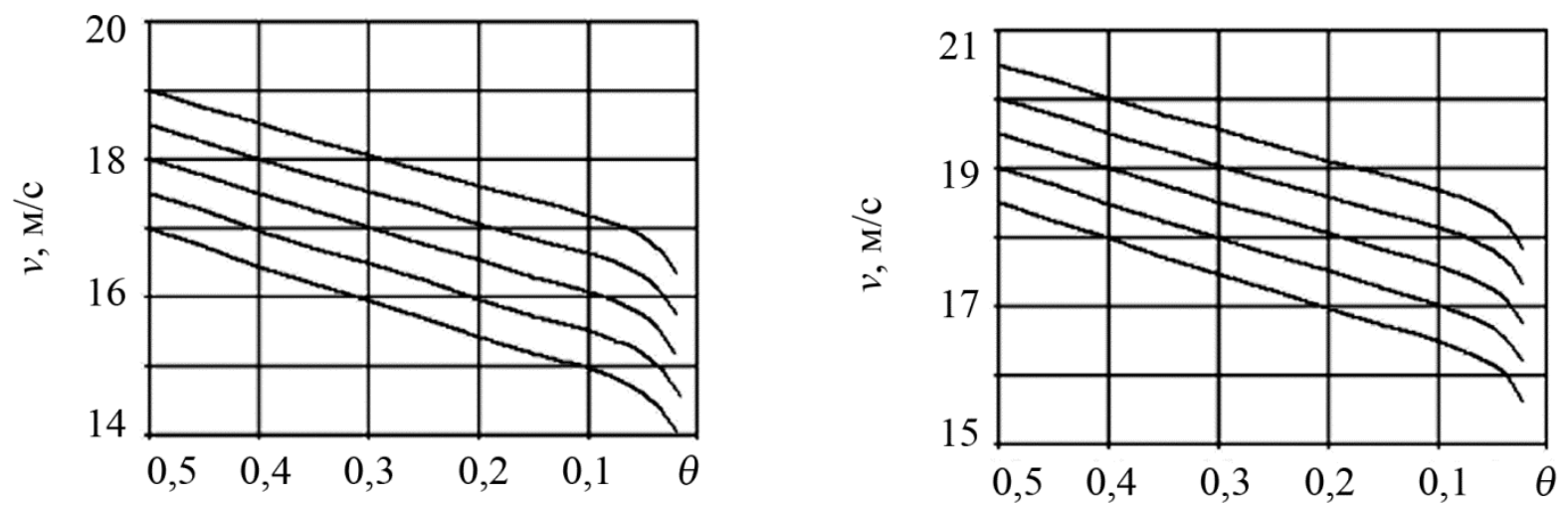

$a$

6

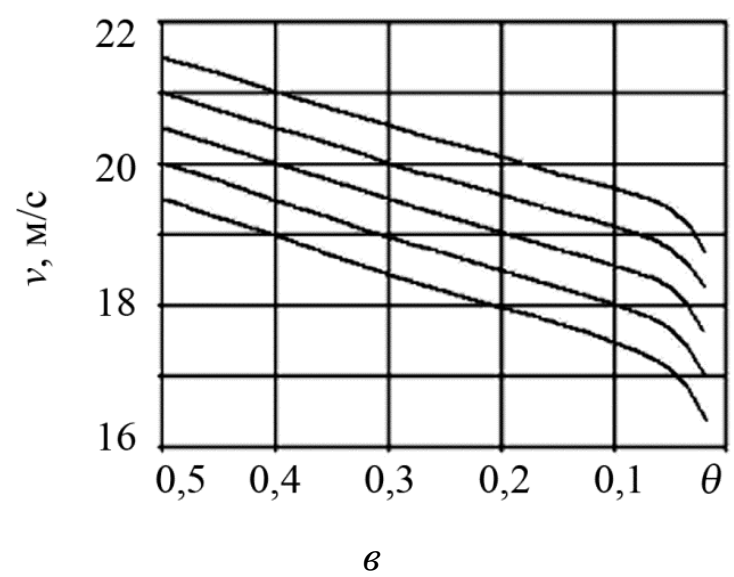

Рис. 21. Зависимость скорости инструмента от пористости при прессовании в замкнутом объеме порошка ПЖ4М2 для $K_{м}=1000: a-\tilde{f}=0,2 ; \sigma-\tilde{f}=0,4 ; 6-\tilde{f}=0,6$ 

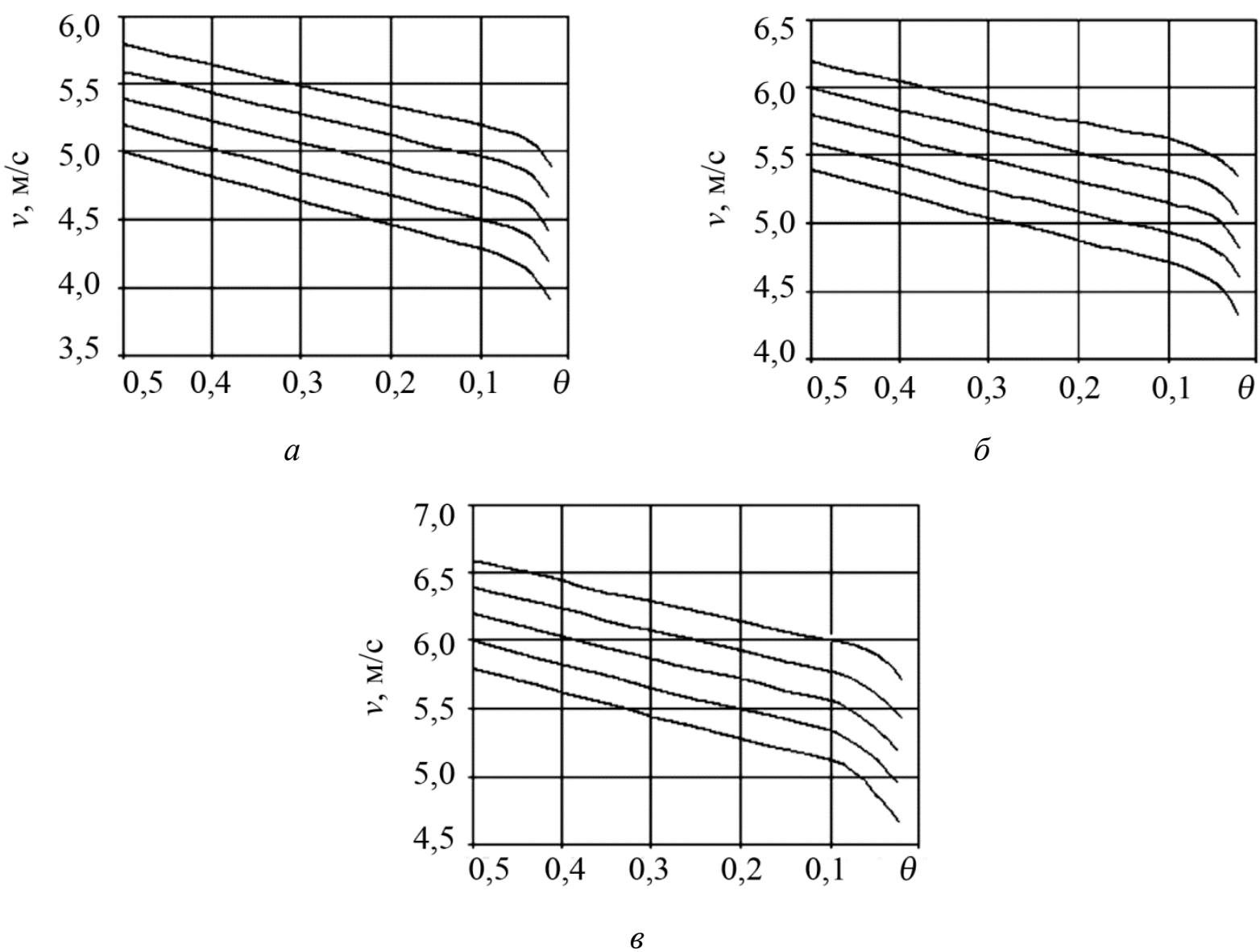

Рис. 22. Зависимость скорости инструмента от пористости при прессовании в замкнутом объеме порошка ПЖ4М2 для $K_{м}=10000: a-\tilde{f}=0,2 ; \sigma-\tilde{f}=0,4 ; в-\tilde{f}=0,6$ 

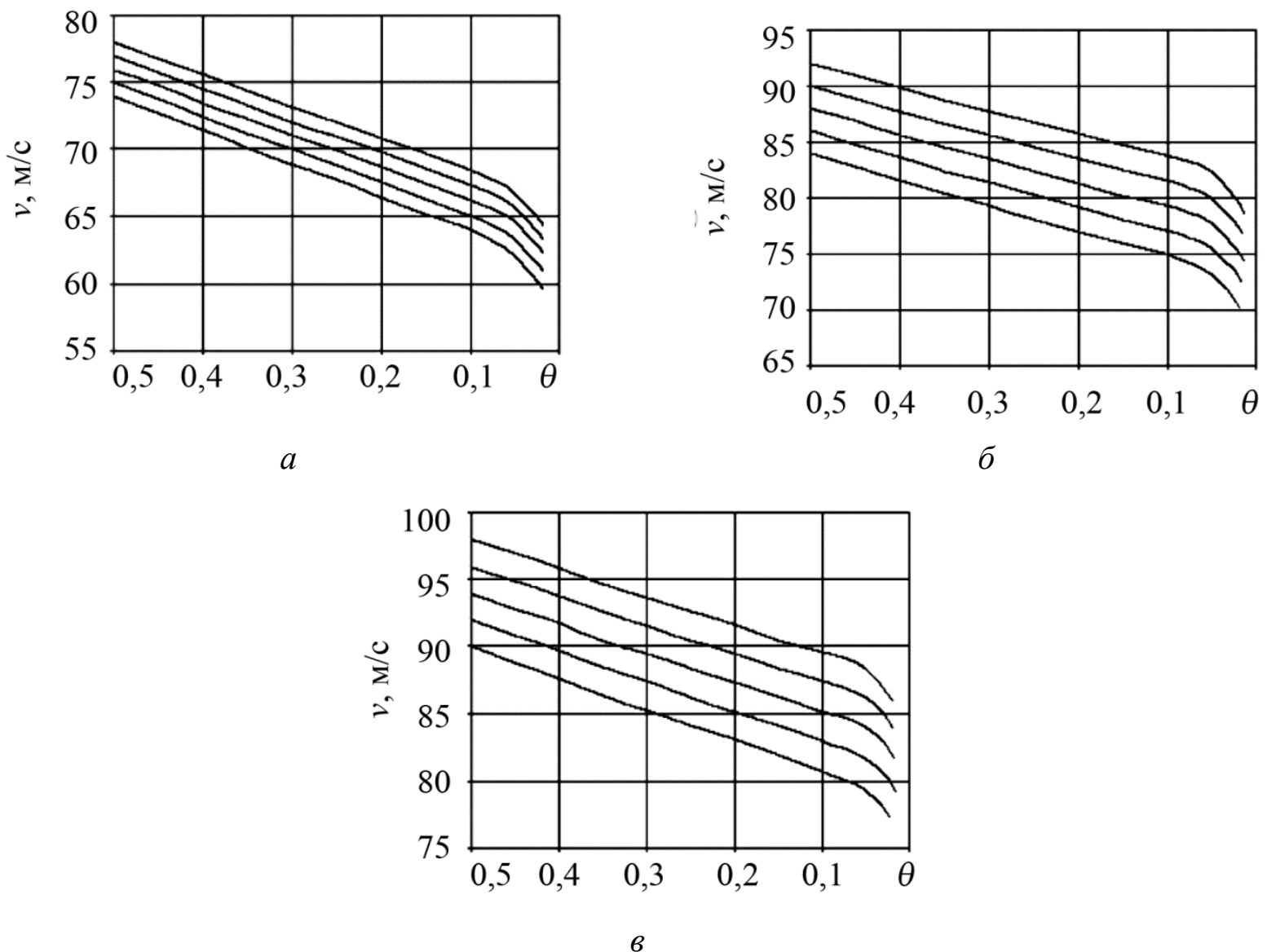

Рис. 23. Зависимость скорости инструмента от пористости при прессовании в замкнутом объеме некомпактного титана для $K_{M}=100: a-\tilde{f}=0,2 ; \sigma-\tilde{f}=0,4 ; в-\tilde{f}=0,6$ 

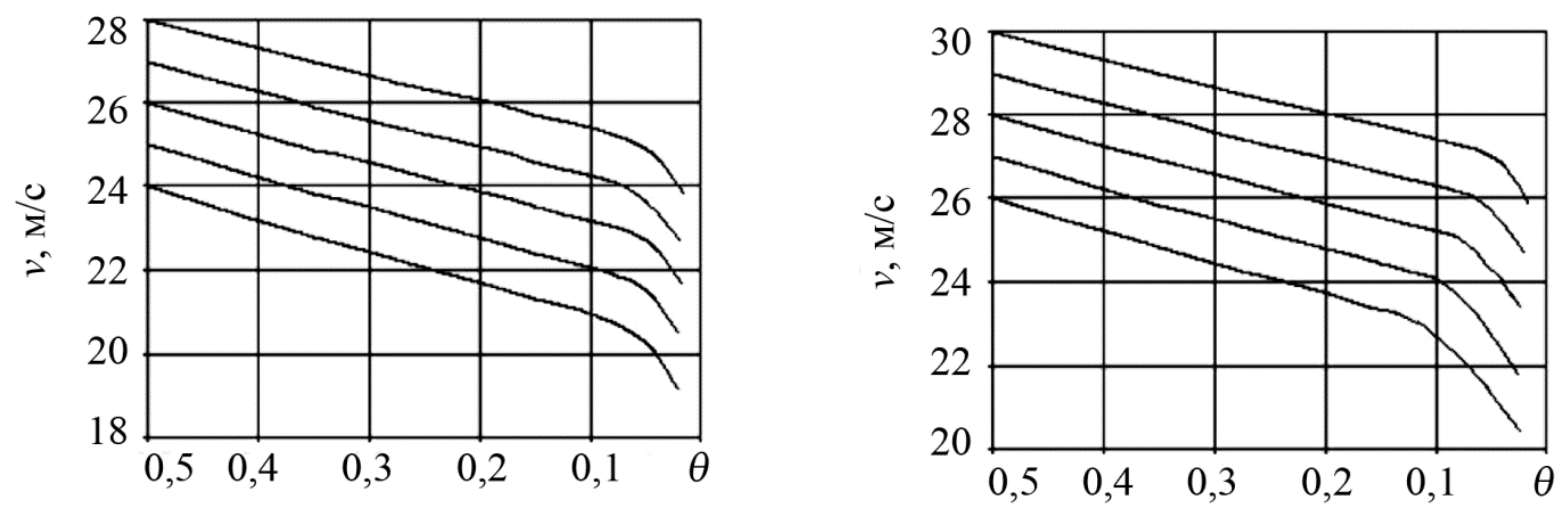

$a$

$\sigma$

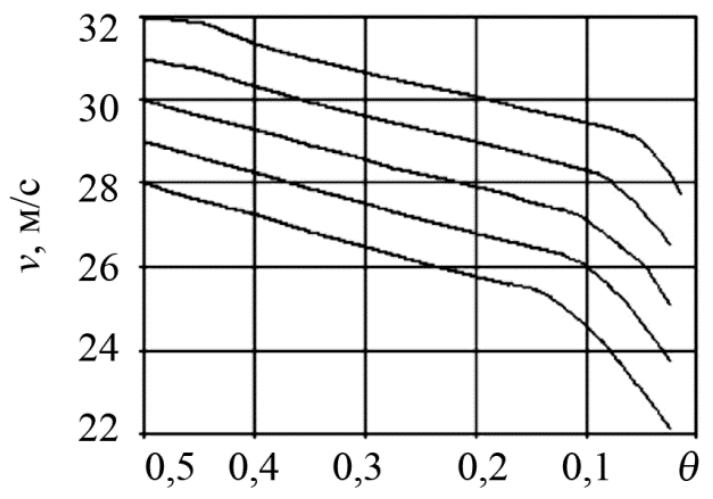

B

Рис. 24. Зависимость скорости инструмента от пористости при прессовании в замкнутом объеме некомпактного титана для $K_{м}=1000: a-\tilde{f}=0,2 ; \sigma-\tilde{f}=0,4 ; в-\tilde{f}=0,6$ 


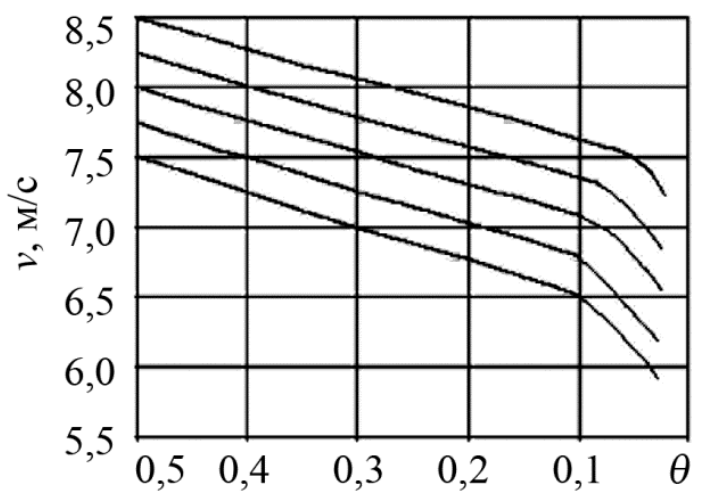

$a$

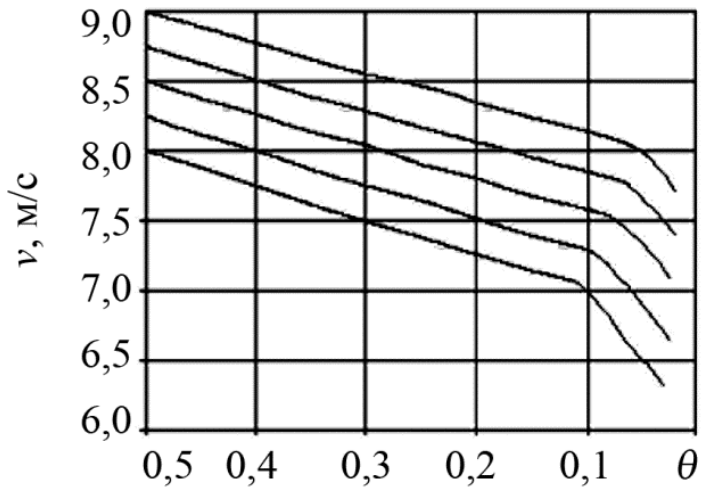

б

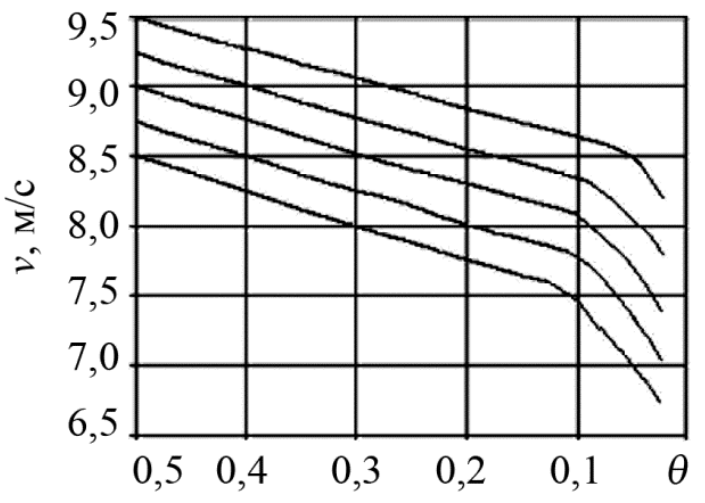

B

Рис. 25. Зависимость скорости инструмента от пористости при прессовании в замкнутом объеме некомпактного титана для $K_{м}=10000: a-\tilde{f}=0,2 ; \sigma-\tilde{f}=0,4 ; в-\tilde{f}=0,6$

C практической точки зрения это означает, что для определения начальной скорости инструмента при ударном выдавливании некомпактного материала на стадии уплотнения порошка для конкретного материала и значения $K_{s}$ допустимо использовать любую из зависимостей, приведенных на рис. 20-25, независимо от значения параметра $\tilde{f}$.

\section{4. Выводы}

Построена математическая модель динамического прессования порошка в цилиндрическом контейнере, позволяющая в зависимости от начальной пористости, размеров заготовки, массы и скорости инструмента, сил трения определять величину и характер распределения остаточной пористости. Показано, что при прессовании массивным ударником и плотности, близкой к теоретической, остаточная пористость распределена по высоте практически равномерно независимо от условий деформирования. При высоких скоростях инструмента остаточная пористость по высоте заготовки распределена неравномерно даже при отсутствии трения в силу волнового характера процесса.

Рассмотрено влияние начальной скорости инструмента и отношения его массы к массе заготовки, варьировавшегося в диапазоне $10^{2} \div 10^{4}$, на скорость распространения ударных волн в порошке. Показано, что в исследуемом диапазоне параметров динамического нагружения существует линейная зависимость между скоростью фронта ударной волны и скоростью инструмента. Определена величина давления на фронте ударной волны. 
Построена математическая модель процесса ударного выдавливания некомпактной заготовки через коническую матрицу при условии, что плотности исходной заготовки и пресс-остатка различны. Она основывается на суперпозиции решений задачи о прессовании порошка в цилиндрической пресс-форме и задачи об ударном выдавливании несжимаемого материала. Показано, что независимо от соотношения масс заготовки и инструмента оптимальное значение угла конусности матрицы, при котором скорость инструмента, необходимая для осуществления процесса, минимальна, меняется от $25 \div 30^{\circ}$ до $35 \div 40^{\circ}$ в зависимости от трения.

Для компьютерного моделирования процессов динамического прессования некомпактных материалов разработан программный комплекс DSPressing. Он позволяет выполнить расчет с одновременным замедленным просмотром процесса распространения ударной волны, графически отображает изменение во времени основных параметров процесса.

\section{Литература}

1. Обработка металлов взрывом / А. В. Крупин, В. Я. Соловьев, Г. С. Попов, М. Р. Кръстев. М. : Металлургия, 1991. - 496 с.

2. Дмитриев А. М., Воронцов А. Л. Технология ковки и объемной штамповки. Часть 1. Объемная штамповка выдавливанием : учебник для вузов с грифом Минобразования РФ. М. : Высшая школа, 2002. - 400 с.

3. Роман О. В., Горобцов В. Г. Импульсное нагружение порошковых материалов // Актуальные проблемы порошковой металлургии / под ред. О. В. Романа, В. С. Аруначалама М. : Металлургия, 1990. - С. 78-99.

4. Belyakov G. V., Rodionov V. N., Samosadnyi V. P. Heating of porous material under impact compression // Combustion explosion and shock waves. - 1977. - Vol. 13, iss. 4. P. 524-528. - DOI: 10.1007/BF00744803.

5. Герасимов А. В., Кректулева Р. А. Численное моделирование деформирования и разрушения функционально градиентных пористых материалов при взрывном и ударном нагружении // Механика композиционных материалов и конструкций. -1999. - Т. 5, № 3. C. 94-106.

6. Alekseev Yu. L., Ratnikov V. P., Rybakov A. P. Shock adiabats of porous metals // Journal of Applied Mechanics and Technical Physics. - 1971. - Vol. 12, no. 2. - P. 257-262. DOI: $10.1007 / \mathrm{BF} 00850698$.

7. Anisichkin V. F. Shock compression of porous bodies // Combustion explosion and shock waves. - 1979. - Vol. 15, iss. 6. - P. 796-799. - DOI: 10.1007/BF00739873.

8. Высокоскоростное взаимодействие тел / В. М. Фомин, А. И. Гулидов, Г. А. Сапожников, И. И. Шабалин, В. А. Бабаков, В. Ф. Куропатенко, А. Б. Киселев, Ю. А. Тришин, А. И. Садырин, С. П. Киселев, И. Ф. Головлев. - Новосибирск : СО РАН, 1999. - 600 с.

9. Дерибас А. А., Ставер А. М. Ударное сжатие цилиндрических пористых тел // ФГВ, 1974. - Т. 10, № 4. - С. 568-578.

10. Кузьмин Г. Е., Ставер А. М. К определению параметров течения при ударном нагружении порошкообразных материалов // ФГВ, 1973. - Т. 9, № 6. - С. 898-905.

11. Магнитно-импульсная штамповка полых цилиндрических заготовок / А. К. Талалаев, С. П. Яковлев, В. Д. Кухарь, Н. Е. Проскуряков, Е. М. Селедкин, Ю. Г. Нечепуренко. - Тула : Репроникс Лтд., 1998. - 238 с.

12. Нестеренко В. Ф. Импульсное нагружение гетерогенных материалов. - Новосибирск : Наука, 1992. - 200 с.

13. Roman O. V., Mirilenko A. P., Pikus I. M. Theory and technology of the component formation process - effect of high-speed loading conditions on the pressing mechanism // Soviet Powder Metallurgy and Metal Ceramics. - 1989. - Vol. 28, iss. 11. - P. 840-844. DOI: $10.1007 / \mathrm{BF} 01198890$. 
14. Сердюк Г. Г., Свистун Л. И. Ударное прессование металлических порошков (теоретическое исследование). // Реологические модели и процессы деформирования пористых порошковых и композиционных материалов. - Киев : Наук. думка, 1985. - С. 115-126. 15. Hermann W. Constitutive equation for the dynamic compaction of ductile porous materials. // Journal of Applied Physics. - 1969. - Vol. 40, no. 6. - P. 2490-2499. - DOI: 10.1063/1.1658021.

16. Shtertser A. A. Transmission of pressure in porous-media under explosive loading // Combustion explosion and shock waves. - 1988. - Vol. 24, iss. 5. - P. 610-615.

17. Butcher B. M., Carroll M. M., Holt A. C. Shock wave compaction of porous aluminum // J. Appl. Phys. - 1974. - Vol. 45, no. 9. - P. 3864-3875. - DOI: 10.1063/1.1663877.

18. Carroll M. M., Holt A. C. Steady waves in ductile porous solids // J. Appl. Phys. - 1973. Vol. 44, no. 10. - P. 4388-4392. - DOI: 10.1063/1.1661970.

19. Davison L. Shock-wave structure in porous solids // J. Appl. Phys. - 1971. - Vol. 42, no. 13. P. 5503-5512. - DOI: 10.1063/1.1659971.

20. Hǿrlück S., Dimon P. Statistics of shock waves in a two-dimensional granular flow // Physical Review E. - 1999. - Vol. 60, no. 1. - P. 671-686. - DOI: 10.1103/PhysRevE.60.671.

21. Nunziato J. W., Walsh E. K. One-dimensional shock waves in uniformly distributed granular materials // Int. J. Solids and Struct. - 1978. - Vol. 14, no. 8. - P. 681-689. DOI: 10.1016/0020-7683(78)90006-9.

22. Numerical Simulation of Shock-Wave Processes in Elastic Media and Structures. Part I: Solving Method and Algorithms / M. V. Ayzenberg-Stepanenko, G. G. Osharovich, E. N. Sher, Z. Sh. Yanovitskaya // Journal of Mining Science. - 2012. - Vol. 48, no. 1. - P. 76-95. DOI: $10.1134 / \mathrm{S} 1062739148010091$.

23. Simulation of the action of a shock wave on titanium alloy / S. A. Afanas'eva, N. N. Belov, V. V. Burkin, E. F. Dudarev, A. N. Ishchenko, K. S. Rogaev, A. N. Tabachenko, M. V. Khabibullin, N. T. Yugov // Journal of Engineering Physics and Thermophysics. - 2017. - Vol. 90, no. 1. - P. 24-34. - DOI: 10.1007/s10891-017-1535-8.

24. Roman O. V., Shmuradko V. T., Tarasov G. D. Curve of the dynamic compressibility of powder media // Journal of Engineering Physics and Thermophysics. - 2006. - Vol. 79, no. 4. P. 817-823.

25. Measuring the Nanohardness of Commercial Submicrocrystalline Aluminum Alloys Produced by Dynamic Pressing / O. A. Chikova, E. V. Shishkina, A. N. Petrova, I. G. Brodova // The Physics of Metals and Metallography. - 2014. - Vol. 115, no. 5. - P. 523-528. DOI: $10.1134 / \mathrm{S} 0031918 \mathrm{X} 14050044$.

26. Dynamic Pressing of Titanium for Producing an Ultrafine-Grained Structure / E. V. Shorokhov, I. N. Zhgilev, D. V. Gunderov, A. A. Gurov // Russian Journal of Physical Chemistry B. - 2008. Vol. 2, no. 2. - P. 251-254. - DOI: 10.1134/S1990793108020139.

27. Рогозин В. Д. Взрывная обработка порошковых материалов. - Волгоград : Политехник, 2002. - $136 \mathrm{c}$.

28. Kinelovskii S. A., Maevskii K. K. Model of the behavior of the mixture with different properties of the species under high dynamic loads // Journal of Applied Mechanics and Technical Physics. - 2013. - Vol. 54, no. 4. - P. 524-530. - DOI: 10.1134/S0021894413040020.

29. Vogler T. Shock Wave Perturbation Decay in Granular Materials // J. dynamic behavior mater. - 2015. - Vol. 1. - P. 370-387. - DOI 10.1007/s40870-015-0033-3.

30. Shtern M. B., Kartuzov E. V. Formation and propagation of shock waves in highly porous materials // Powder Metallurgy and Metal Ceramics. - 2016. - Vol. 55, no. 3-4. - P. 134-140. DOI: $10.1007 / \mathrm{s} 11106-016-9788-\mathrm{x}$.

31. Лейцин В. Н. Модель реагирующей порошковой среды // Вестник Томск. гос. ун-та : общенаучный периодический журнал : бюллетень оперативной технической информации. Томск : ТГУ, 2001. - № 5. - 40 с. 
32. Boltachev G. Sh., Kaygorodov A. S., Volkov N. B. Densification of the granular medium by the low amplitude shock waves // Acta Mechanica. - 2009. - Vol. 207. - P. 223-234. DOI: $10.1007 / \mathrm{s} 00707-008-0127-2$.

33. Shock-wave compaction of the granular medium initiated by magnetically pulsed accelerated striker / G. Sh. Boltachev, N. B. Volkov, V. V. Ivanov, A. S. Kaygorodov // Acta Mechanica. - 2009. - Vol. 204. - P. 37-50. - DOI: 10.1007/s00707-008-0046-2.

34. Modeling and optimization of uniaxial magnetic pulse compaction of nanopowders / E. A. Olevsky, A. A. Bokov, G. Sh. Boltachev, N. B. Volkov, S. V. Zayats, A. M. Ilyina, A. A. Nozdrin, S. N. Paranin // Acta Mech. - 2013. - Vol. 224. - P. 3177-3195. DOI: $10.1007 / \mathrm{s} 00707-013-0939-6$.

35. Boltachev G. Sh., Volkov N. B., Chingina E. A. Nanopowders in Dynamic Magnetic Pulse Compaction Processes // Nanotechnologies in Russia. - 2014. - Vol. 9, no. 11-12. - P. 650-659. DOI: $10.1134 / \mathrm{S} 1995078014060056$.

36. Uniaxial Compaction of Nanopowders on a Magnetic Pulse Press / A. A. Bokov, G. Sh. Boltachev, N. B. Volkov, S. V. Zayats, A. M. Il'ina, A. A. Nozdrin, S. N. Paranin, E. A. Olevskii // Technical Physics. - 2013. - Vol. 58, no. 10. - P. 1459-1468. DOI: $10.1134 / \mathrm{S} 106378421310006 \mathrm{X}$.

37. Федотов А. Ф., Амосов А. П., Радченко В. П. Моделирование процесса прессования порошковых материалов в условиях самораспространяющегося высокотемпературного синтеза. М. : Машиностроение-1, 2005. - 282 с.

38. Киселев А. Б., Юмашев М. В. Деформирование и разрушение при ударном нагружении. Модель повреждаемой термоупругопластической среды // ПМТФ. - 1990. - Т. 31, № 5. C. $116-123$.

39. Годунов С. К., Роменский Е. И. Элементы механики сплошных сред и законы сохранения. - Новосибирск : Научная книга, 1998. - 267 с.

40. Bardet J. P., Proubet J. Application of micromechanics to incrementally nonlinear constitutive equations for granular media // Int. Conf. on micromechanics of granular media "Powders and Grains", Clermont-Ferrand, 4-8 September 1989 : proceedings / ed. by J. Biarez, R. Gouvrès. - 1989. - P. 265-273.

41. Resnyansky D., Bourne N. K. Shock-wave compression of a porous material // J. Appl. Phys. - 2004. - Vol. 95, no. 4. - P. 760-1769. - DOI: 10.1063/1.1640460.

42. Boshoff-Mostert L., Viljoen H.J. Comparative study of analytical methods for Hugoniot curves of porous materials // J. Appl. Phys. - 1999. - Vol. 86, no. 3. - P. 1245-1254. DOI: $10.1063 / 1.370878$.

43. Fenton G., Grady D., Vogler T. Shock Compression Modeling of Distended Mixtures // J. dynamic behavior mater. - 2015. - Vol. 1. - P. 103-113. - DOI: 10.1007/s40870-015-0021-7.

44. Shen H., Ahrens T. J., O'Keefe J. D. Shock wave induced vaporization of porous solids // J. Appl. Phys. - 2003. - Vol. 93. - P. 5167-5174. - DOI: 10.1063/1.1563035.

45. Нигматулин Р. И. Основы механики гетерогенных сред. - М. : Наука, 1978. - 336 с.

46. Dunin S. Z., Surkov V. V. Dynamics of the closing of pores at the shock-wave front // Journal of Applied Mathematics and Mechanics. - 1979. - Vol. 43, iss. 3. - P. 550-558.

47. Крайко А. Н., Миллер Л. Г., Ширковский И. А. О течении газа в пористой среде с поверхностями разрыва пористости // ПМТФ. - 1982. - № 1. - С. 111-118.

48. Жданович Г. М. Теория прессования металлических порошков. - М. : Металлургия, 1969. $-264 \mathrm{c}$.

49. Ivanov V. V., Nozdrin A. A. Method of determining dynamic adiabatic compression curves of powders // Technical Physics Letters. - 1997. - Vol. 23. - P. 527-528. - DOI: 10.1134/1.1261734.

50. Nowacki W. K. Stress Waves in Non-Elastic Solids. - Oxford : Pergamon Press, 1978. $182 \mathrm{p}$. 
51. Проскуряков Н. Е., Орлов С. Ю., Череватый Р. С. Влияние скорости деформирования на динамический предел текучести // Механика деформируемого твердого тела и обработка металлов давлением : сб. науч. тр. - Тула : ТулГУ, 2001. - Ч. 1. - С. 134-138.

52. Carroll M. M., Kim K. T., Nesterenko V. F. The effect of temperature on viscoplastic pore collapse // J. Appl. Phys. - 1986. - Vol. 59, no. 6. - P. 1962-1967. - DOI: 10.1063/1.336426.

53. Поляков А. П., Залазинская Е. А. Ударное прессование заготовки из некомпактного металлического сырья // Изв. ВУЗов. Цветная металлургия. - 2003. - № 1. - С. 30-35.

54. Green R. J. A plasticity theory for porous solids // Int. J. Mech. Sci. - 1972. - Vol. 14. P. 215-224. - DOI: 10.1016/0020-7403(72)90063-X.

55. Zalazinskii A. G., Polyakov A. A., Polyakov A. P. On plastic compression of a porous body // Mechanics of Solids. - 2003. - Vol. 38, no. 1. - P. 101-110.

56. Колачев Б. А., Ливанов В. А., Буханова А. А. Механические свойства титана и его сплавов. - М. : Металлургия, 1974. - 544 с.

57. Поляков А. П., Мокроусова М. С. Математическое моделирование процесса динамического прессования порошкового материала // КШП. ОМД. - 2004. - № 2. C. 20-22. - C. 27-30.

58. Polyakov P. The Effect of parameters of dynamic loading on the propagation character of shock waves in a powder // Russian Journal of Non-Ferrous Metals. - 2009. - Vol. 50, no. 1. P. 33-38. - DOI: 10.3103/S106782120901009X.

59. Друянов Б. А. Прикладная теория пластичности пористых тел. - М. : Машиностроение, 1989. - 168 c.

60. Залазинский А. Г. Пластическое деформирование структурно-неоднородных материалов. Екатеринбург : УрО РАН, 2000. - 492 с.

61. Поляков А. П. Ударное выдавливание прутковой заготовки через коническую матрицу // Изв. ВУЗов. Цветная металлургия. - 2004. - № 4. - С. 50-54.

62. Григорьев А. К., Рудской А. И. Деформация и уплотнение порошковых материалов. М. : Металлургия, 1992. - 192 с.

63. Поляков А. П. Ударное выдавливание заготовки с учетом малой сжимаемости материала // Изв. ВУЗов. Черная металлургия. - 2006. - № 3. - С. 32-37.

64. Polyakov A. P. Power Parameters of the Impact Pressing Process of an Incompact Wire Stock // Russian Journal of Non-Ferrous Metals. - 2007. - Vol. 48, no. 2. - P. 136-142. DOI: $10.3103 / \mathrm{S} 1067821207020125$. 